\title{
Coronavirus: Scientometrics of 50 Years of Global Scientific Productions
}

\author{
Farshid Danesh $^{1}$ iD, Somayeh GhaviDel ${ }^{2}$ iD
}

1. Information Management Research Department, Regional Information Center for Science and Technology (RICeST), Shiraz, Iran

2. Department of knowledge and Information Science, School of Psychology and Educational Sciences, Kharazmi University, Tehran, Iran

\section{ABSTRACT}

Background: Scientometrics studies are one of the most efficient methods of quantitative evaluation of the scientific outputs of valuable information and citation databases for understanding and observing the status of scientific publications in different subject areas. The main aim of this article was to study the 50 years of Coronavirus scientific publications in the world.

Materials \& Methods: This applied research was carried out using scientometrics methods and an analytical approach. The statistical population of this article includes 5128 Coronavirus subject area documents indexed on the WoS from 1970 to 2019. The keywords were extracted from MeSH and analyzed using Excel 2016.

Results: Data analysis showed that the highest science production was in 2005, and the highest citation number was in 2019. "Enjuanes L." is the most proliferated author, the United States, the most productive country, and the University of Hong Kong, the top organization in Coronavirus in the last half-century.

Conclusion: The results showed, there is a direct relationship between the Coronavirus outbreaks and the amount of Scientific Publications in this area in the World. The quality of the researchers' productions in this area can be deliberated by scientific methods and researchers' self-citation has affected their h-index. For health care researchers, policymakers, and planners, it is necessary to be aware of the results of scientific studies of strategic and vital research areas, such as Coronavirus, to identify more appropriate therapeutic goals, make better decisions, and provide more effective solutions in the shortest time.

Keywords: Coronavirus; COVID-19; 2019-nCoV; Coronavirus Disease 2019; Scientometrics

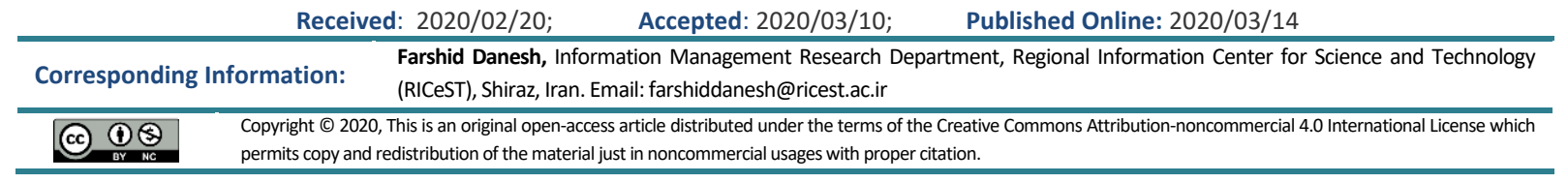

Use your device to scan and read the article online

Danesh F, Ghavidel S. Coronavirus: Scientometrics of 50 Years of global scientific productions. Iran J Med Microbiol. 2020; 14 (1):1-16

Download citation: BibTeX | RIS | EndNote | Medlars | ProCite | Reference Manager | RefWorks Send citation to: $\otimes_{\text {Mendeley }} \mathbf{z}$ zotero $\mathbb{H}_{\text {RefWorks }}$

\section{Introduction}

Coronavirus is a common disease between humans and animals (zoonosis) $(\mathbf{1}, \mathbf{2})$, which is enveloped, nonsegmented, and has positive-sense single-stranded RNA virus (3). Genotypically and serologically, there are four groups, with approximately thirty types of coronaviruses common to humans, mammals, and birds. So far, considerable attention has paid to international cases of Pathogenesis and pathology (5-7). COVID-19 identified by WHO in Wuhan, China, at the beginning of 2020 (6, 5, 2 ), is considered the most dangerous virus of this family these days and has raised severe health concerns for all countries of the world (13). The virus causes severe respiratory and intestinal infections in animals and humans (14) and subsequently leads to death (15).

With the increase of scientific publications, the importance of observing such studies has become more 
critical in assessing the effects of scientific output on the medical sciences and has become an integral part of monitoring the performance of organizations (20). Investigating the existing capacities helps policymakers and research managers in the ranking of performance quality assessment, correct and normative budget allocation (21).

Scientometrics studies in international citation databases such as WOS are one of the essential tools for observing medical research processes and developments (22). Now (March 2020), in line with the challenging and global spread of Coronavirus, medical scientists do many types of research and publish papers to find innovative solutions to prevent the virus. To this end, medical scientists, using various indexes and software to analyze Coronavirus, observe and evaluate research outputs and present their findings to science and technology researchers and policymakers.

Some of the most essential literatures related to scientific representation of medical sciences utilizing scientometrics methods and indicators in Iran and internationally include Coronaviruses bibliographic analysis (14), Nipah Virus (23), MERS-CoV (24), HPV (25), Parasitology (26), Diabetes (27), Surgery (28), Neonatal Healths (29).

A review of the literature indicates that different scientometrics tools have attracted the attention of medical scholars and have been useful in representing the structure of medical science knowledge by analyzing this method. Given the immense and strategic importance of Coronavirus and the increasing scientific publicity of this subject, the study of scientometrics of Coronavirus is of great importance.

The main issue of this paper is to determine the status of the knowledge structure of international Coronavirus research outputs. Representing the scientific structure from different angles will guide Coronavirus specialists and researchers and policymakers in the Ministry of Health and medical science associations. Based on the elaborated theoretical framework, the primary purpose of this paper was to analyze half a century of scientific publications of Coronavirus in the world using scientific methods and tools. It is essential to review the process of scientific publishing, the type of resources, citations to articles, and identify the top journals, researchers, countries, and organizations in this subject area to achieve this goal from 1970 to 2019.

\section{Materials and Methods}

This applied research was carried out using scientometrics methods and an analytical approach. The statistical population of this article includes 5128 Coronavirus subject area documents indexed on the WOS from 1970 to 2019. The keywords were extracted from the Mesh browser and analyzed using Excel 2016 software.

\section{Results}

\section{Coronavirus international publication trend}

Data analysis showed that the highest percentage of the scientific output of Coronavirus was in 2005 (6.8\%), 2004 (6.78\%), and 2006 (5.92\%), respectively (Figure1).

Different Source Types of Coronavirus Scientific Publications Frequency Distribution

This article aimed to review the scientific publications of the Coronavirus, which are in the four types of Articles (4474), Meeting abstracts (313), Proceedings paper (290), and Reviews (235) respectively (Figure 2).

\section{Coronavirus Citation Analysis}

The total number of citations received in the last 50 years of the Coronavirus scientific publications is 165451. There are 3271 self-citations at the same time. Coronavirus scientific output in 2019 received the highest number of citations, 11385 . The highest selfcitation was in 357 in 2014.

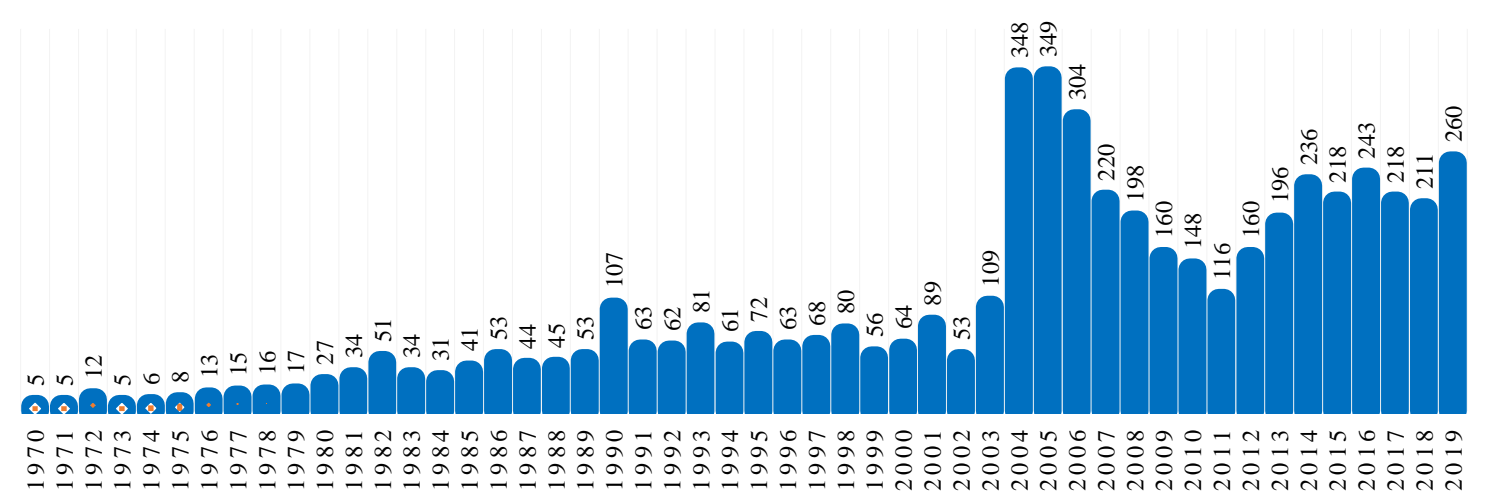

Figure 1. Percentile of Coronavirus science production trend (1970-2019) 


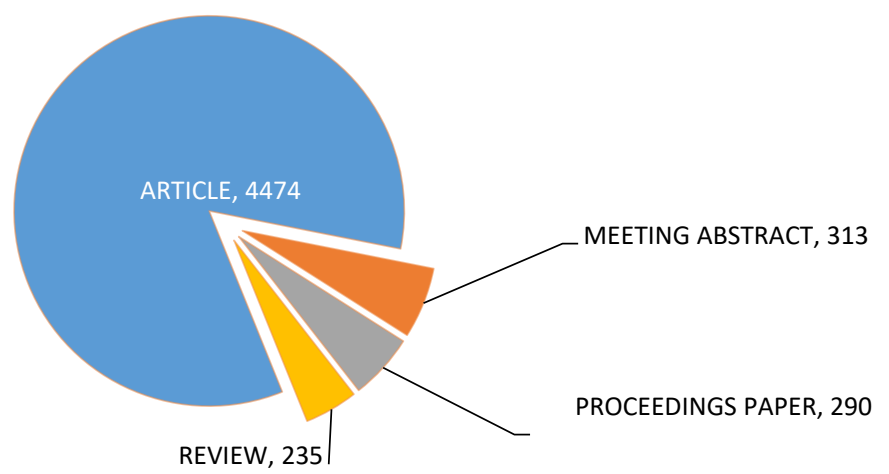

Figure 2. Different Source Types of Coronavirus Scientific Publications (1970-2019)

Table 1. Coronavirus Citation Analysis (1970-2019)

\begin{tabular}{|c|c|c|c|c|c|c|c|c|c|c|c|}
\hline Year & 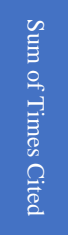 & 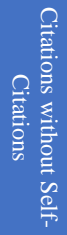 & Citation & Self-Citation & 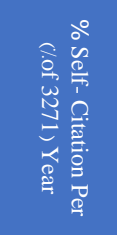 & Year & 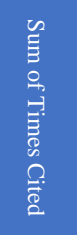 & 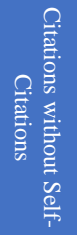 & Citation & Self- Citation & 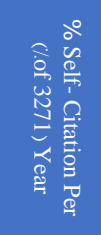 \\
\hline 1970 & 252 & 251 & 1 & 1 & 0.000306 & 1995 & 2003 & 1994 & 1505 & 9 & 0.002751 \\
\hline 1971 & 143 & 143 & 8 & 0 & 0 & 1996 & 8 & 0 & 1340 & 8 & 0.002446 \\
\hline 1972 & 704 & 701 & 38 & 3 & 0.000917 & 1997 & 413 & 389 & 1778 & 24 & 0.007337 \\
\hline 1973 & 384 & 383 & 55 & 1 & 0.000306 & 1998 & 41 & 389 & 1639 & 9 & 0.002751 \\
\hline 1974 & 255 & 0 & 58 & 255 & 0.077958 & 1999 & 98 & 87 & 1666 & 11 & 0.003363 \\
\hline 1975 & 197 & 0 & 67 & 197 & 0.060226 & 2000 & 415 & 397 & 1631 & 18 & 0.005503 \\
\hline 1976 & 431 & 429 & 70 & 2 & 0.000611 & 2001 & 85 & 64 & 2083 & 21 & 0.00642 \\
\hline 1977 & 500 & 497 & 98 & 3 & 0.000917 & 2002 & 57 & 44 & 1373 & 13 & 0.003974 \\
\hline 1978 & 393 & 391 & 200 & 2 & 0.000611 & 2003 & 753 & 527 & 2733 & 226 & 0.069092 \\
\hline 1979 & 1 & 0 & 215 & 1 & 0.000306 & 2004 & 675 & 365 & 5968 & 310 & 0.094772 \\
\hline 1980 & 3 & 0 & 250 & 3 & 0.000917 & 2005 & 16050 & 15758 & 8876 & 292 & 0.089269 \\
\hline 1981 & 4 & 0 & 387 & 4 & 0.001223 & 2006 & 751 & 634 & 8811 & 117 & 0.035769 \\
\hline 1982 & 1001 & 994 & 527 & 7 & 0.00214 & 2007 & 180 & 81 & 8059 & 99 & 0.030266 \\
\hline 1983 & 1329 & 1315 & 385 & 14 & 0.00428 & 2008 & 253 & 184 & 8986 & 69 & 0.021094 \\
\hline 1984 & 1204 & 1201 & 404 & 3 & 0.000917 & 2009 & 444 & 388 & 6905 & 56 & 0.01712 \\
\hline 1985 & 4 & 0 & 504 & 4 & 0.001223 & 2010 & 661 & 616 & 7404 & 45 & 0.013757 \\
\hline 1986 & 7 & 0 & 518 & 7 & 0.00214 & 2011 & 898 & 865 & 6381 & 33 & 0.010089 \\
\hline 1987 & 263 & 248 & 672 & 15 & 0.004586 & 2012 & 566 & 510 & 6075 & 56 & 0.01712 \\
\hline 1988 & 94 & 88 & 819 & 6 & 0.001834 & 2013 & 9202 & 8866 & 7654 & 336 & 0.102721 \\
\hline 1989 & 141 & 136 & 802 & 5 & 0.001529 & 2014 & 630 & 273 & 10586 & 357 & 0.109141 \\
\hline 1990 & 165 & 146 & 1107 & 19 & 0.005809 & 2015 & 157 & 14 & 10151 & 143 & 0.043718 \\
\hline 1991 & 612 & 592 & 1189 & 20 & 0.006114 & 2016 & 370 & 256 & 11068 & 114 & 0.034852 \\
\hline 1992 & 173 & 161 & 1284 & 12 & 0.003669 & 2017 & 910 & 810 & 9260 & 100 & 0.030572 \\
\hline 1993 & 818 & 808 & 1842 & 10 & 0.003057 & 2018 & 1059 & 989 & 9243 & 70 & 0.0214 \\
\hline 1994 & 958 & 936 & 1391 & 22 & 0.006726 & 2019 & 345 & 226 & 11385 & 119 & 0.03638 \\
\hline \multicolumn{12}{|c|}{ Sum of Self- Citations: $\mathbf{3 2 7 1}$} \\
\hline \multicolumn{12}{|c|}{ Sum of received Citations: 165451} \\
\hline
\end{tabular}

\section{Coronavirus Top Journals}

Table 2 contains data from the top 10 Coronavirus journals ranked by impact factor. Of the journals listed in Table 2, the US publishes 12 and the Netherlands 5 Coronavirus journals. The highest impact factor is 9.58. The Journal of Virology has the highest number of citations and self-citations with 37309 and 5734, respectively.

\section{Top Coronavirus Researchers}

Table 3 lists the top ten Coronavirus researchers based on the number of scientific publications in the last 50 years. "Enjuanes, L." with 114 publications, has the first place. However, the highest $h$-index belongs to "Yuen, KY" which is 49. It should be noted that "Yuen, KY" has 862 has the self-citation; which is the highest. Of the 5,128 Coronavirus documents in the 
last 50 years, 888 (over $17 \%$ ) were published by the top 10 researchers.

\section{The Most Proliferated Countries in Coronavirus}

Of the 98 countries that have published the most Coronavirus scientific papers, the United States, China, and the Netherlands are the most proliferated countries (Figure 3).

\section{The Most Proliferated Organizations in Coronavirus}

Among the most proliferated organizations in Coronavirus scientific publications, The University of Hong Kong, Chinese Academy of Sciences, and Utrecht University have ranked first to third, respectively.

Table 2. Ranking of Coronavirus Journals based on Impact Factor (1970-2019)

\begin{tabular}{|c|c|c|c|c|c|c|c|c|}
\hline Resource Title & Citations & $\begin{array}{l}\text { Pure } \\
\text { Citations }\end{array}$ & $\begin{array}{l}\text { Self- } \\
\text { Citation }\end{array}$ & Country & Article Influence Score & $\begin{array}{l}\text { Eigen } \\
\text { Factor }\end{array}$ & $\begin{array}{l}\text { Impact factor } \\
\text { (IF) }\end{array}$ & $\begin{array}{c}\text { Quartile } \\
\text { (Q) }\end{array}$ \\
\hline $\begin{array}{l}\text { Proceedings of the National } \\
\text { Academy of Sciences of the } \\
\text { United States of America }\end{array}$ & 6403 & 6324 & 79 & USA & 4.493 & 1.02189 & 9.58 & Q1 \\
\hline Emerging infectious diseases & 4182 & 4094 & 88 & USA & 2.725 & 0.05940 & 7.185 & Q1 \\
\hline Journal of Infectious Disease & 2939 & 2889 & 50 & USA & 2.164 & 0.07596 & 5.045 & Q1 \\
\hline Journal of Clinical Microbiology & 2384 & 2329 & 55 & USA & 1.381 & 0.05332 & 4.959 & Q1 \\
\hline Journal of Virology & 37309 & 31575 & 5734 & USA & 1.381 & 0.09997 & 4.324 & Q1 \\
\hline Antiviral Research & 882 & 865 & 17 & Netherlands & 1.137 & 0.01597 & 4.13 & Q1 \\
\hline $\begin{array}{c}\text { The Journal of Biological } \\
\text { Chemistry }\end{array}$ & 2971 & 2916 & 55 & USA & 1.503 & 0.25223 & 4.106 & Q2 \\
\hline Viruses Basel & 888 & 863 & 25 & Switzerland & 1.221 & 0.02409 & 3.811 & Q2 \\
\hline Journal of Clinical Virology & 997 & 980 & 17 & Netherlands & 0.970 & 0.01530 & 3.02 & Q2 \\
\hline Journal of General Virology & 6498 & 6185 & 313 & England & 0.883 & 0.01877 & 2.809 & Q2 \\
\hline
\end{tabular}

Table 3. Ranking of Coronavirus Researcher based on Record Number (1970-2019)

\begin{tabular}{|c|c|c|c|c|c|c|c|}
\hline Author & Affiliation & Record & $\%$ of $\mathbf{5 1 2 8}$ & h-index & Citation & Self-Citation & Pure Citation \\
\hline Enjuanes L & $\begin{array}{l}\text { Department of Molecular and Cell Biology, National Center } \\
\text { of Biotechnology (CNB-CSIC), Madrid, Spain }\end{array}$ & 114 & 2.223 & 42 & 4105 & 603 & 3502 \\
\hline Perlman S & $\begin{array}{l}\text { Department of Microbiology and Immunology, University of } \\
\text { Iowa, Iowa City, Iowa, USA }\end{array}$ & 107 & 2.087 & 36 & 2914 & 266 & 2648 \\
\hline Yuen KY & $\begin{array}{l}\text { Department of Microbiology, Li Ka Shing Faculty of } \\
\text { Medicine, The University of Hong Kong, Pokfulam, Hong } \\
\text { Kong Special Administrative Region, China }\end{array}$ & 107 & 2.087 & 49 & 10105 & 862 & 9243 \\
\hline Weiss SR & $\begin{array}{l}\text { Department of Microbiology, Perelman School of Medicine, } \\
\text { University of Pennsylvania, Philadelphia, PA, USA }\end{array}$ & 97 & 1.892 & 36 & 3424 & 459 & 2965 \\
\hline Baric RS & $\begin{array}{l}\text { Department of Epidemiology, University of North Carolina, } \\
\text { Chapel Hill, NC, USA }\end{array}$ & 85 & 1.658 & 36 & 3676 & 283 & 3393 \\
\hline Rottier PJM & $\begin{array}{l}\text { Virology Division, Department of Infectious Diseases and } \\
\text { Immunology, Utrecht University, Faculty of Veterinary } \\
\text { Medicine, Utrecht, the Netherlands }\end{array}$ & 84 & 1.638 & 41 & 5146 & 346 & 4800 \\
\hline Drosten C & $\begin{array}{l}\text { Institute of Virology, Charité Universitätsmedizin, Berlin, } \\
\text { Germany. }\end{array}$ & 82 & 1.599 & 38 & 8500 & 299 & 8201 \\
\hline Liu DX & $\begin{array}{l}\text { Guangdong Province Key Laboratory of Microbial Signals \& } \\
\text { Disease Control, and Integrative Microbiology Research } \\
\text { Centre, South China Agricultural University, Guangzhou, } \\
\text { China }\end{array}$ & 73 & 1.424 & 30 & 1867 & 455 & 1412 \\
\hline Makino S & $\begin{array}{l}\text { Department of Microbiology and Immunology, The } \\
\text { University of Texas Medical Branch, Galveston, Texas, USA }\end{array}$ & 72 & 1.404 & 33 & 2904 & 358 & 2546 \\
\hline Woo PCY & $\begin{array}{l}\text { State Key Laboratory of Emerging Infectious Diseases, The } \\
\text { University of Hong Kong, Pokfulam, Hong Kong }\end{array}$ & 67 & 1.307 & 34 & 4831 & 558 & 4273 \\
\hline
\end{tabular}




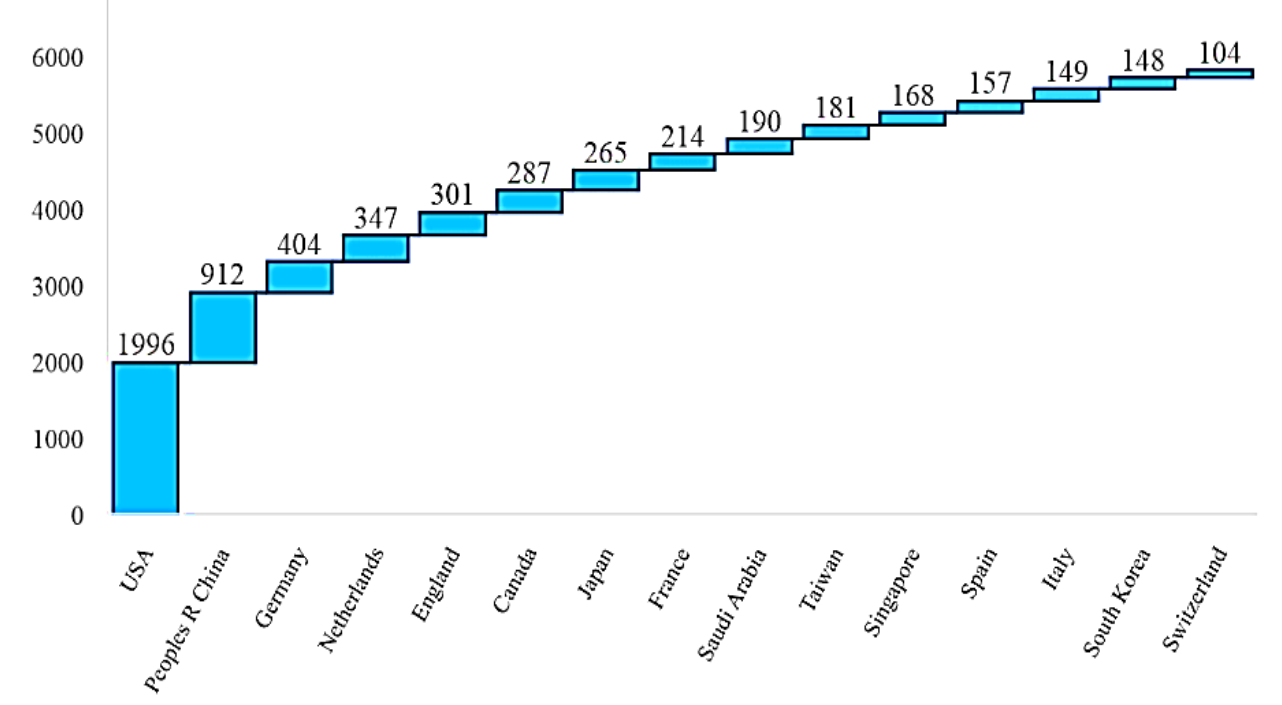

Figure 3. The Most Proliferated Countries in Coronavirus (1970-2019)

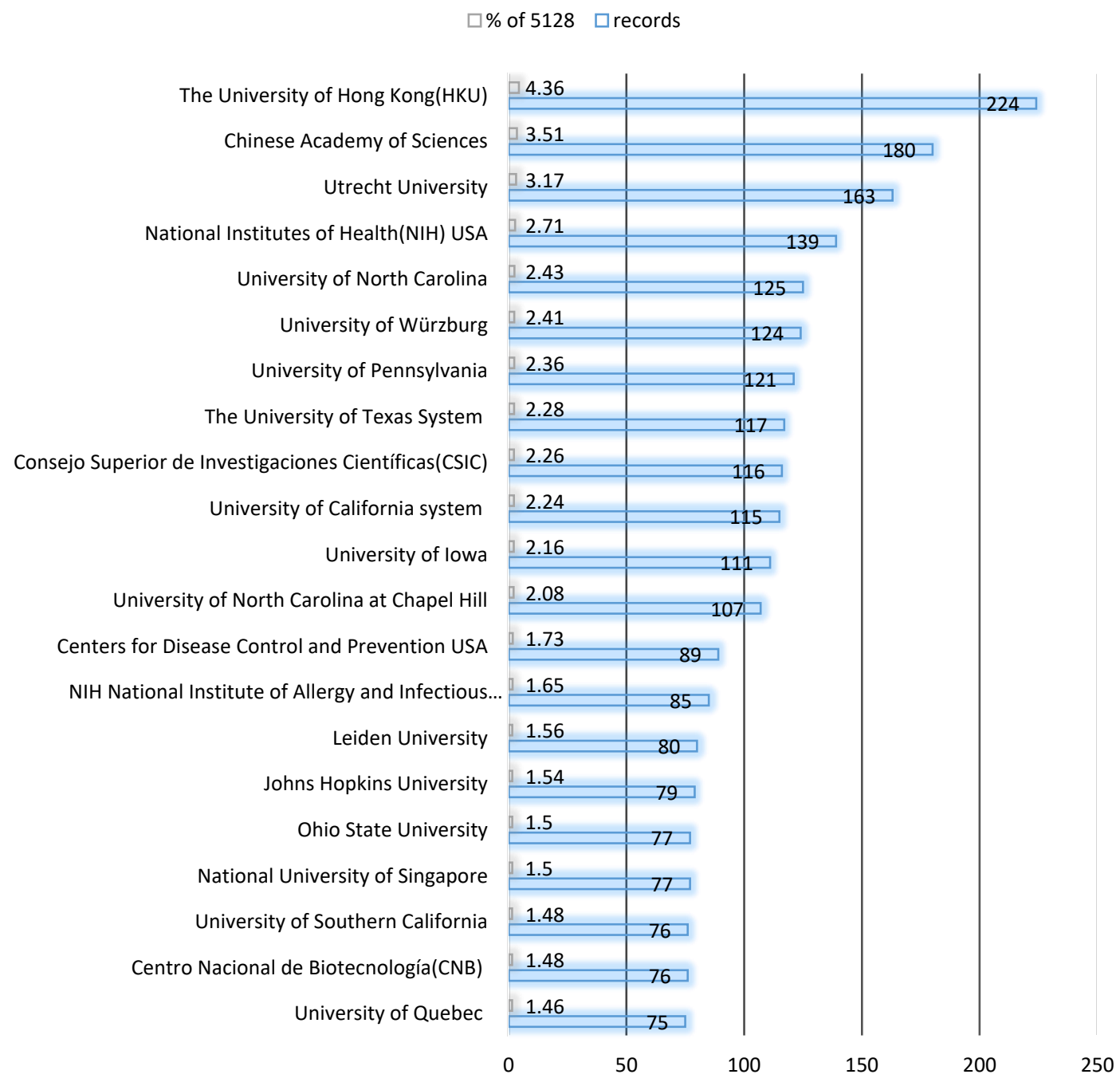

Figure 4. The Most Proliferated Organizations in Coronavirus (1970-2019) 


\section{Discussion}

In the past 50 years, the fewest frequency of Coronavirus scientific publications were indexed in the WoS from 1970 to 1975 and the most documents were published in 2005, 2004, and 2006. The scientific publications trend of this paper is in line with the results of Bonilla-Aldana et al. (14). The United States, the Journal of Virology, the University of Hong Kong, and "Enjuanes L." are the most proliferated ones in the Coronavirus publications, which is in line with the results of Zyoud (24). In terms of increased research activities and scientific publications, the results of this article are similar to those of Shirshahi et al. (26), Morovati and Sotudeh (27), and Emami et al. (25).

\section{Conclusion}

Considering the new and widespread wave of COVID19 infection in China and especially in Iran, considerable studies and clinical trials are ongoing. The findings of this article can be useful to scientists who are currently researching COVID19, especially Iranian specialists. It recommended that the paper summary will design in brochure format and widely disseminate to the researchers through the Iranian Microbiology Society.

\section{Acknowledgment}

In this regard, we appreciate the Infectious diseases experts for their valuable comments.

\section{Conflict of Interest}

Authors declared no conflict of interests. 


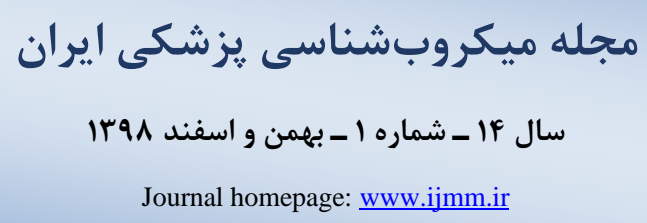

\title{
كروناويروس: علمسنجى ينجاه سال توليد علم جهانى
}

\author{
فرشيد دانش ا**id) سميه قويدل

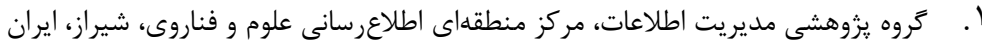

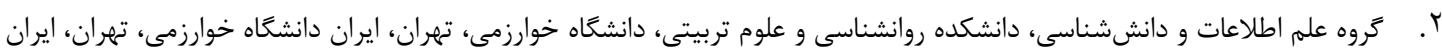

\section{جكيله}

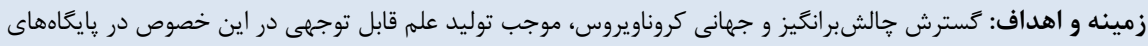

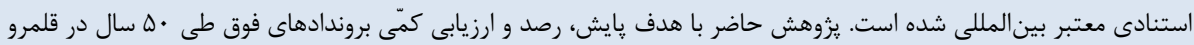
كروناويروس بهمطالعه يرداخته است.

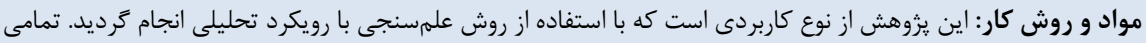

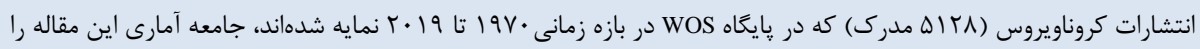

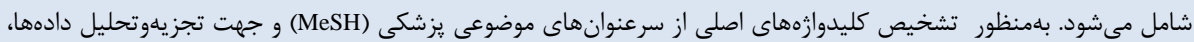
نرمافزار Excel Eه به كار رفت.

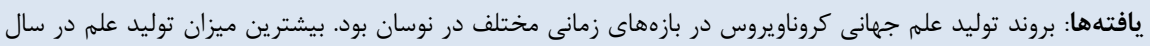

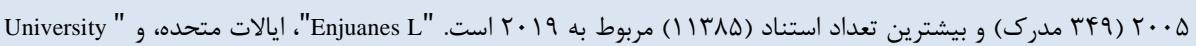

"of Hong Kong نتيجه كيرى: نتايج نشان داد بين Outbreak كاى كروناويروس و ميزان توليد علم جهانى اين قلمرو رابطه مستقيمى وجود دارد.

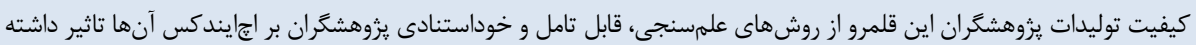

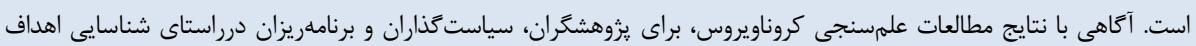

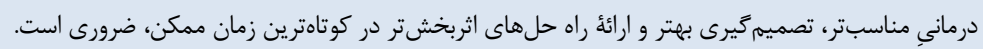

$$
\text { كليد وازهها: كروناويروس؛ كروناويروس جديد؛ كوويد-9 1؛ علمسنجى. }
$$

اطلاعات مقاله

تاريخجهُ مقاله

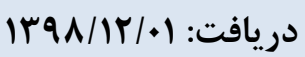

يذيرش:••

انتشار آنلاين:

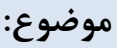

ويروسشناسى

نويسندهُ مسئول:

فرشيد دانش، كروه يُوهشى مديريت

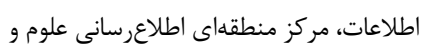

فناروى، شيراز، ايران

ايميل: farshiddanesh@ricest.ac.ir
حاد تنفسى سارس (SARS-CoV) را ايجاد مى كنند. كروناويروسها تاكنون توجه زيادى از موارد بيمارىزايى (Pathogenesis) و آسيبشناسى (pathology) بينالمللى را متوجه خود كردهاند (-هونه رئه (V

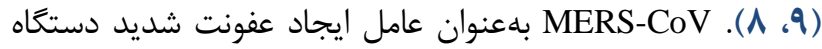
تنفسى تحتانى در انسان، نرخ مرى و ميرى بيشتر از SARS-CoV

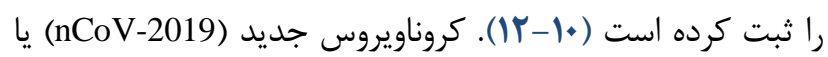
كوويد-19 (COVID-19) در شروع سال • • • ب در شهر ووهان جين

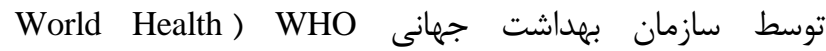
(Organization
كروناويروس (Coronavirus)، از بيمارىهاى مشترك بين

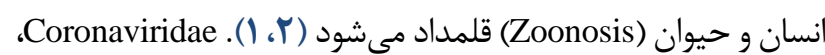

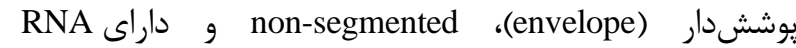
تكرشتهاى مثبت (Positive-sense) است (ب). از نظر زنوتاييى و سرولوزى در :جهار نوع آلفا، بتا، گاما و دلتا گروهبندى شدهاند و تقريبا سى نوع كروناويروس در انسان، يستانداران و پرند كروناويروسهاى انسانى (MCOV-EMC) از نوع آلفا و بتا هستند (F). اين خانواده بزرگ، عامل طيف وسيعى از بيمارىهاى ويروسى (F) هستند و از سرماخوردگى گرفته تا بيمارىهاى شديدتر مانند

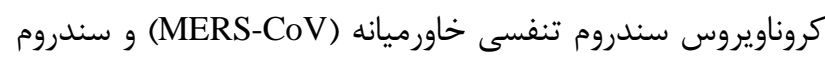


موضوعى كروناويروس، در خارج از كشور دو يزوهش وجود دارد كه در

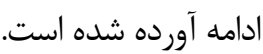

تحليل كتابشناختى كروناويروسها: MERS- SARS-CoV،

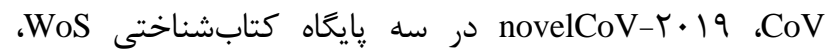

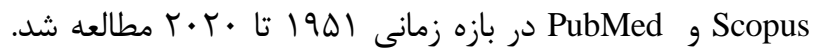

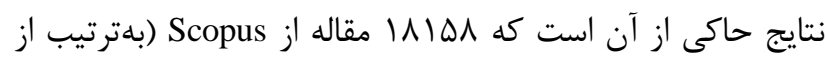

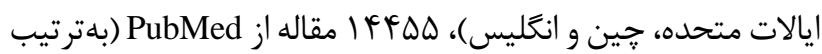

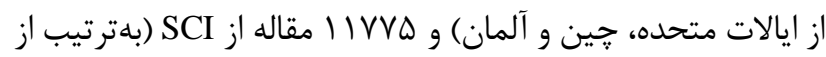

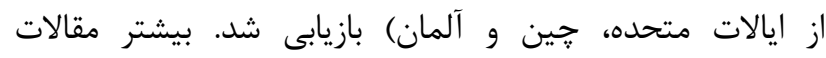

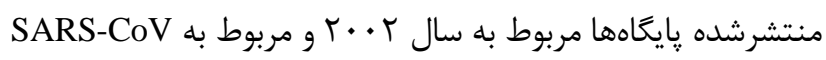
سيس MERS-CoV بوده است. نتايج اين يزوهش نشان داد، ايالات متحده و جين، نقش اصلى در يزوهشهاى CoV دارند و و امريكا

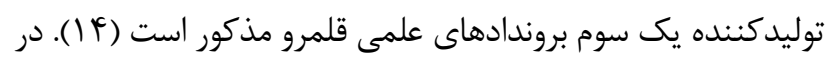
تحليل كتابشناختى كروناويروس سندروم تنفسى خاونى خاورميانه

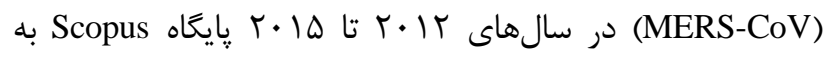

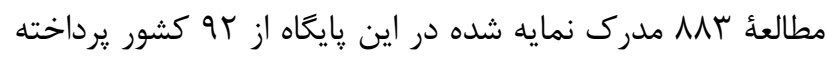
شد. نتايج نشان از رشد سريع انتشارات در اين بازه زمانى را را داشت.

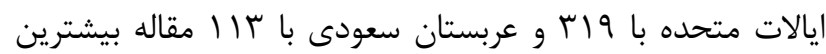
توليد علم را در ميان كشورها به خود اختصاص دادند. در اين ميان

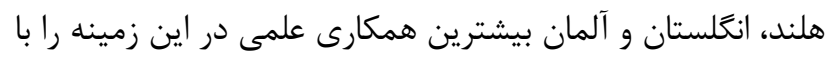

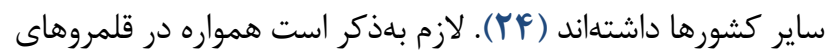
مختلف علوم يزشكى از ابزارها و روشهاى علمسنجى بهره برده شده

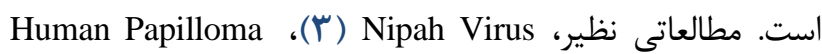

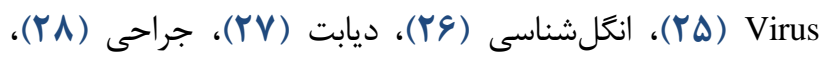

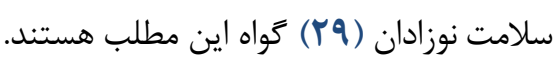

مرور ييشينهها نشانكر اين موضوع است كه ابزارهاى مختلف

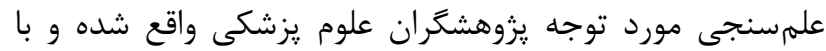

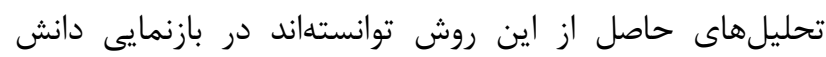

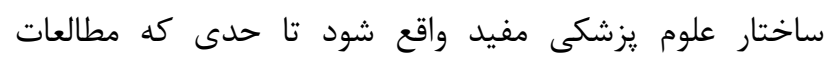

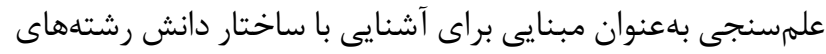

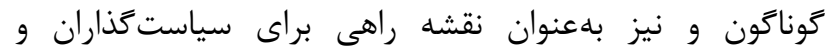

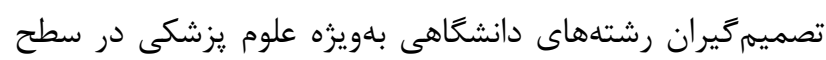

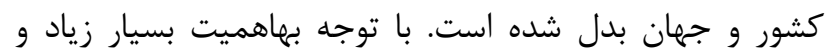

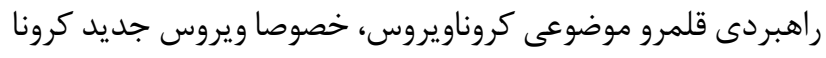
(2019-nCoV) توجه به علمسنجى در اين خصوص اهميت ويزماى دارد. نكاهى بهروند موجود، جريان توليد علم، مراكز و سازمانها اثربخش و و هسته، كشورهاى فعال و يرتوليد و در نهايت معرفى مجلات هسته ترانه
خطرناكترين ويروس خانواده Coronaviridae محسوب شده و هشدار جدى براى تمام كشورهاى جهان بهشمار مىآيد (بال). اين

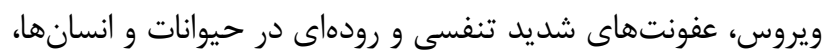

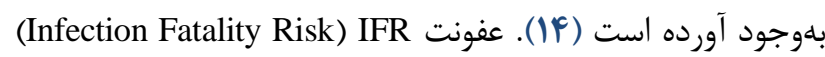

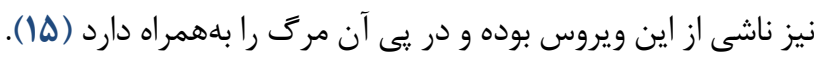
IV بر اساس اطلس منتشر شده توسط دانشخاه جان هإِكينز تا

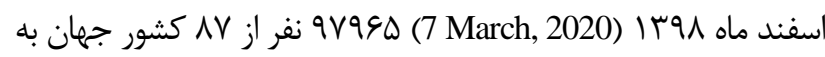

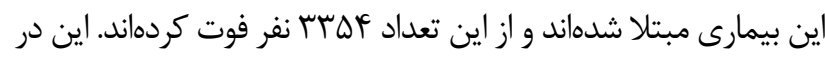

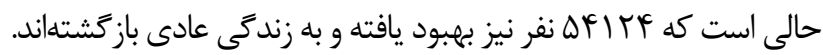
شناسايى و ارزشيابى منظهم بروندادهاى علمى، جهت آكاهى از

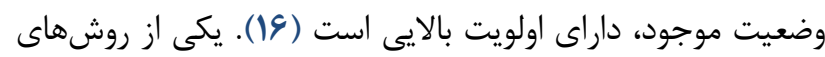

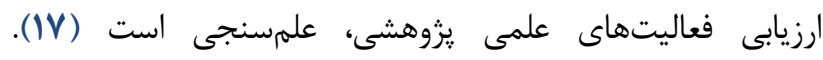
علمسنجى در توصيف، تبيين و بيشبينى وضعيت علمى يزوهشكران

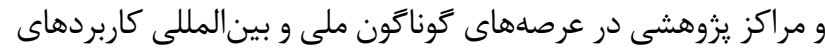

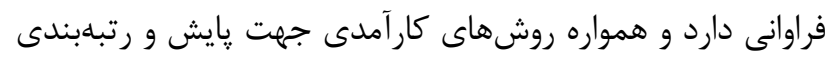

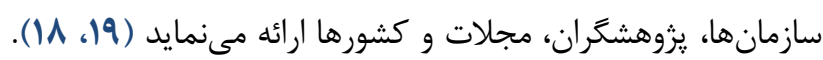

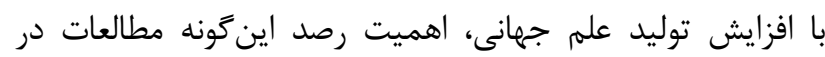

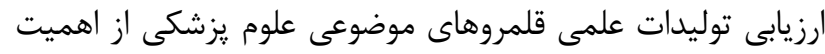

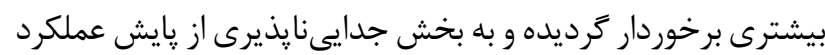

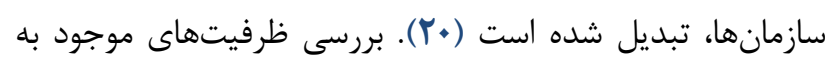

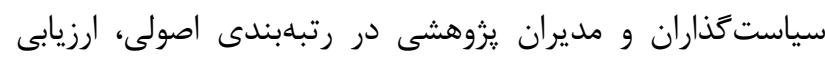

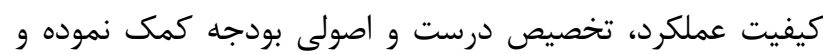

منجر به شناخت بهتر مجموعهها و روندها مىشود (YI). علمسنجى مقالات علمى پايخاههاى استنادى معتبر، يكى از

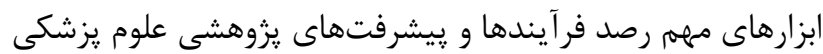

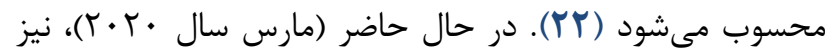

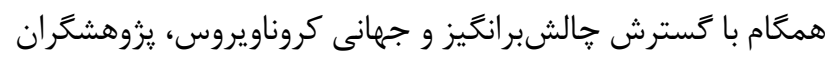
علوم يزشكى نيز درخصوص راههاى بيشكيرى و و درمان اين ويروس

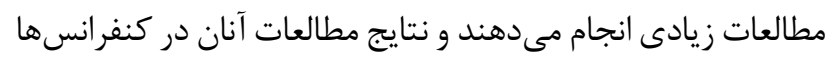
ارائه و در مجلات علمى معتبر منتشر مىشود. در همين راستا

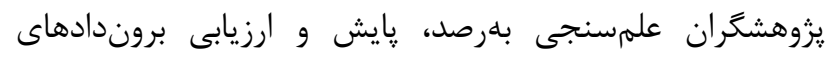

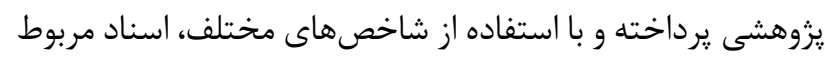

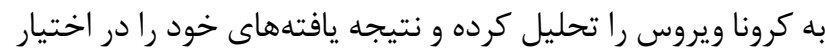
دانشمندان و سياست كذاران علوم يزشكى قرار ميى دهند. در بررسى مطالعات دانشمندان ايران، درخصوص كروناويروس، هيج مقالهايى كه بهروش علمسنجى انجام شده باشد، مشاهده نشد اما در بررسى يِيشينه درخصوص علمسنجى يا كتابسنجى قلمرو 


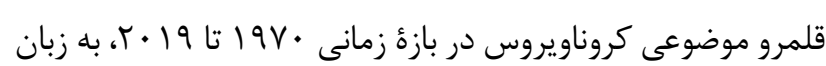
انغليسى و در قالب مقاله است.

يس از مشورت با متخصصان بيمارىهاى تنفسى و عفونى،

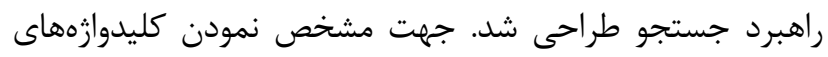
اصلى از مروركر سرعنوانهاى موضوعى يزشكى (MeSH) استفاده

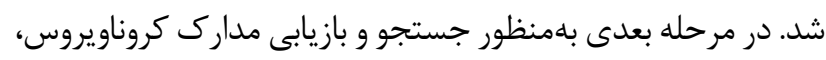

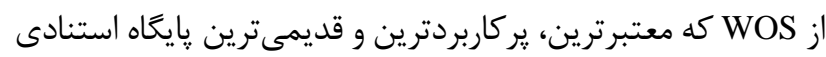

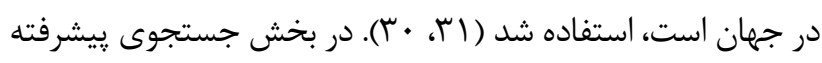

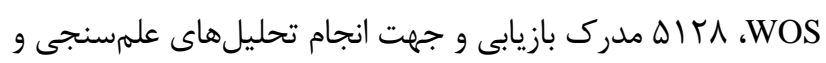

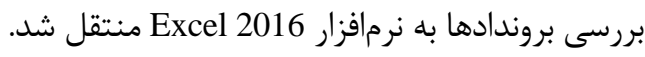

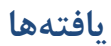

\section{روند انتشارات بين المللى كروناويروس}

دادهاى مندرج در شكل اروند توليد علم جهانى كروناويروس

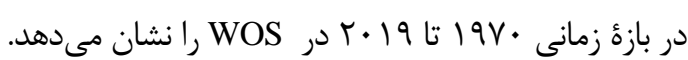

\section{انواع منابع منتشر كننده توليدات علمى كروناويروس}

شكل r. فراوانى انواع توليدات علمى كروناويروس در بازه

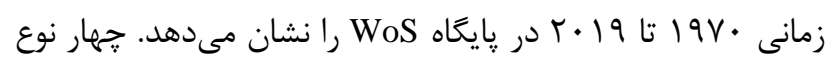

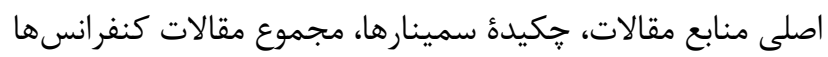
و مقالات مرورى هستند كه بر اساس فراوانى ديده مى مقود.
در قلمرو كروناويروس، در شرايط فعلى بيش از پيش ضرورى بهنظر

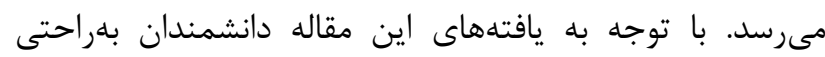

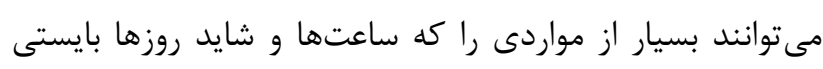

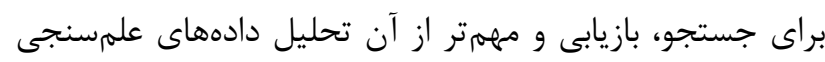

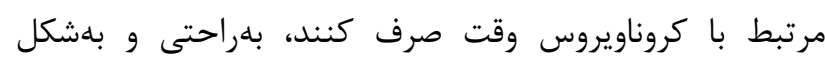
سازمانيافته و تحليلشده در اين مقاله در اختيار داشته باشند. مسألله اصلى اين يزوهش، مشخص نمودن وضعيت بروندادهاى

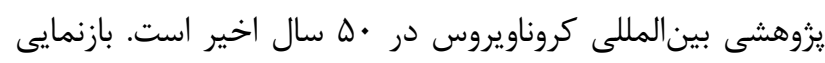

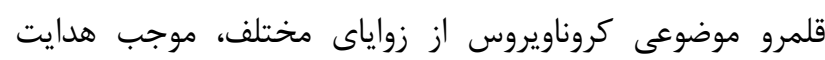

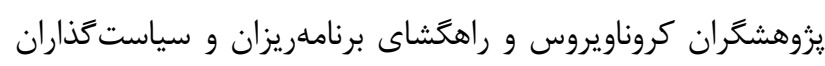

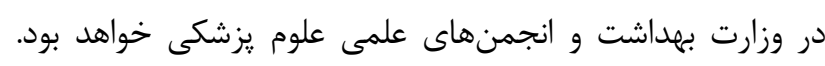

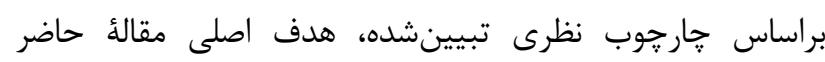

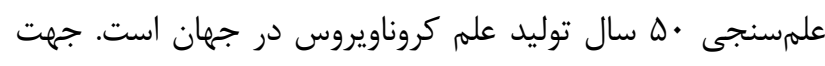

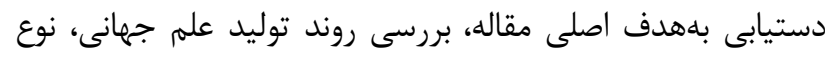

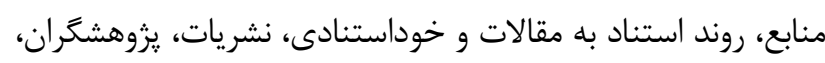

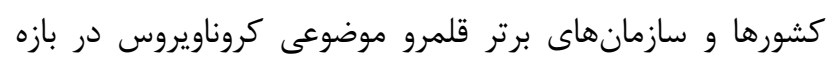

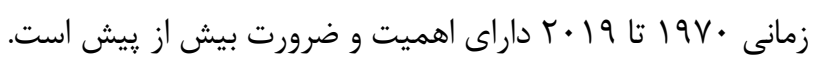

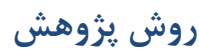

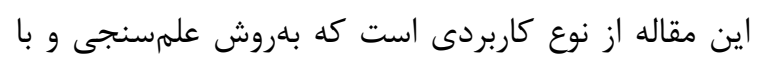

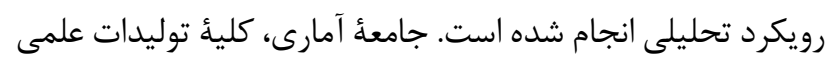

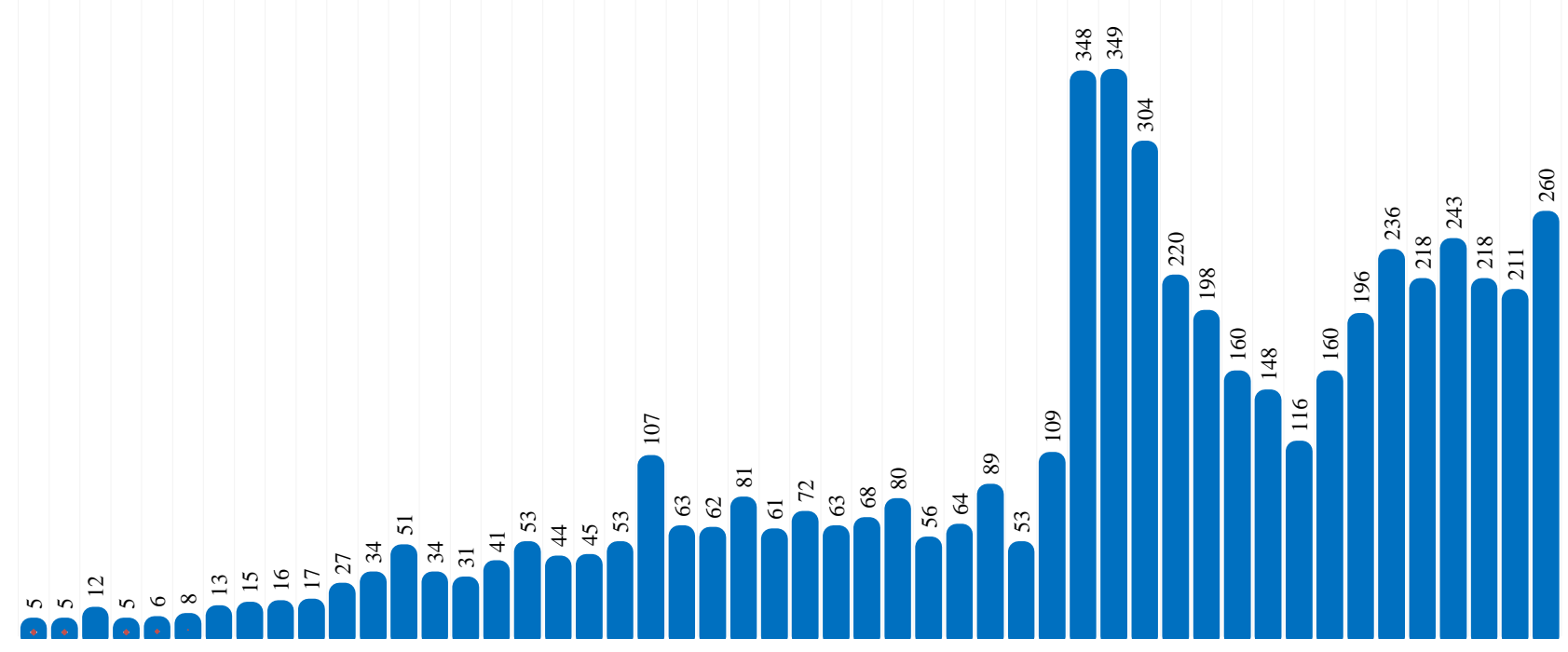

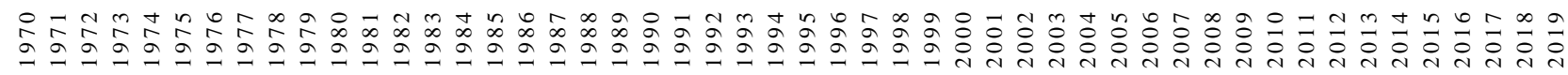

شكل ا. روند توليد علم كروناويروس در 


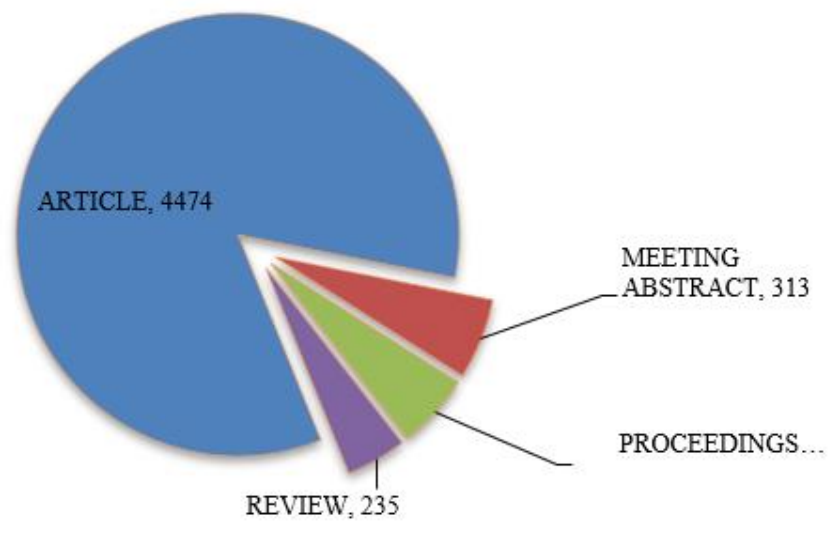

شكل r. انواع منابع منتشركننده توليدات علمى كروناويروس

جدول ا. استنادات دريافتى مقالات قلمرو موضوعى كروناويروس

\begin{tabular}{|c|c|c|c|c|c|c|c|c|c|c|c|}
\hline$\frac{\check{\xi}}{\xi}$ & $\frac{\xi}{\xi}$ & 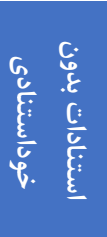 & $\frac{\frac{c}{c}}{\frac{c}{\xi}}$ & $\frac{G}{\frac{G}{G}}$ & 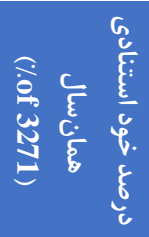 & $\frac{\check{E}}{\xi}$ & $\frac{\xi}{\xi}$ & 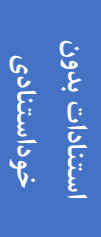 & $\frac{\frac{c}{\xi}}{\frac{c}{\xi}}$ & $\frac{G}{\frac{G}{G}}$ & 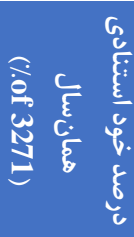 \\
\hline 198. & TAT & $r Q I$ & 1 & 1 & $\cdot / \cdot r \cdot \varphi$ & 1990 & $r \cdot r$ & 1994 & $10 \cdot \Delta$ & 9 & . . . TVQI \\
\hline 1971 & Ifr & Ifr & $\wedge$ & . & . & 1999 & $\wedge$ & . & IrF. & $\wedge$ & . . PrfFe \\
\hline 19VT & $V \cdot f$ & $v \cdot 1$ & ऍ^ & $r$ &.$/ \cdots 91 \mathrm{~V}$ & 1997 & fir & rیq & IVVA & TF & . . . VRrV \\
\hline $19 V \pi$ & rAF & rᄉr & $\Delta \Delta$ & 1 & $\cdot / \cdot r \cdot \varphi$ & 1991 & (i) & rیq & 1949 & 9 & . /.TVDI \\
\hline I9VF & $r \Delta \Delta$ & $\cdot$ & $\Delta \Lambda$ & $r \Delta \Delta$ & $\cdot / \cdot \vee \vee १ \Delta A ~$ & 1999 & 91 & $\wedge \vee$ & 1999 & 11 & אצr...|. \\
\hline $19 \vee \Delta$ & $19 V$ & · & GV & $19 V$ & . $.9 \cdot$ TrG & $r \ldots$ & Fid & rqv & $|\& T|$ & 11 & $\cdot / \cdot \Delta \Delta \cdot r$ \\
\hline 19V8 & FrI & Frq & $\vee \cdot$ & r &.$\ldots 911$ & $r \cdot \cdot 1$ & $\Lambda \Delta$ & $q 4$ & $r \cdot \wedge r$ & $r I$ & . . . get \\
\hline $198 V$ & $\Delta \cdot \cdot$ & fqv & 91 & $r$ &.$/ \cdot 91 \mathrm{~V}$ & $r \cdot r r$ & $\Delta V$ & fF & IrVT & r &.$/ . r q v f$ \\
\hline $197 \wedge$ & एव & एवा & $r .$. & r &. $\mid \ldots 911$ & $r . . r$ & VAT & $\Delta T V$ & TVRr & TYG & .1 .99 .94 \\
\hline $19 \vee 9$ & 1 & . & rID & 1 & $\cdot / \ldots r \cdot 4$ & $r \ldots r$ & sVD & red & $\Delta 99 \wedge$ & щ. &.$/ .9 \mathrm{FVVr}$ \\
\hline 191. & $r$ & . & $r \Delta$. & $r$ &.$/ .9918$ & $r \cdots \Delta$ & $19 \cdot 0$. & $1 \Delta V \Delta \Lambda$ & MAVE & rqT & •/•^৭५९q \\
\hline 1911 & f & . & rAv & r & שTוI./. & r.. & VDI & gMr & 1111 & 118 & $\cdot / \cdot r \Delta \vee G q q$ \\
\hline 1914 & $1 \ldots 1$ & 994 & $\Delta T V$ & v & $\cdot|\cdot r| f$ & $r \cdots v$ & $1 \wedge$ & 11 & $\Lambda \cdot \Delta q$ & 99 & •/.r.rGq \\
\hline 1914 & Irrq & DIM & 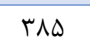 & If & $\cdot /$ FrA & $r \cdots \wedge$ & rar & INF & 1919 & 99 & $\cdot|\cdot r| \cdot q F$ \\
\hline 1914 & $M \cdot r$ & $1 r \cdot 1$ & $f \cdot r$ & r & $\cdot / \cdots 91 \mathrm{~V}$ & $r \cdots q$ & FFF & rM & $99 \cdot \Delta$ & $\Delta \varphi$ & $\cdot / \cdot I V I T$ \\
\hline 1910 & r & · & $\Delta \cdot F$ & r & . . . ITrK & $r \cdot 1$. & 991 & 919 & $V F \cdot F$ & $i \Delta$ &.$/ \cdot 1 r V \Delta V$ \\
\hline 1919 & v & . & $\Delta 11$ & v & $\cdot /$ rIf & $r .11$ & 191 & $\wedge \varepsilon \Delta$ & GKNI & זr & $\cdot / \cdot 1 \cdots \wedge 9$ \\
\hline $191 \mathrm{~V}$ & TET & TYA & GVT & 10 & $\cdot \cdot \cdot \varphi \Delta \wedge \varepsilon$ & $r \cdot 1 r$ & $\Delta \varphi \varphi$ & $\Delta 1$. & $G \cdot V \Delta$ & $\Delta \varphi$ &.$/ \cdot I V I T$ \\
\hline 1911 & 94 & $\wedge$ & 119 & 9 & $\cdot / \cdot$ IAFF & $r \cdot 1 r$ & $q T \cdot r$ & 1M99 & VGQF & G & . II. TVTI \\
\hline 1919 & $|f|$ & G & $\Lambda \cdot r$ & $\Delta$ & $\cdot / \cdot 1 \Delta T_{q}$ & r.lf & gr. & TVr & $1 \cdot \Delta \wedge \varepsilon$ & $r \Delta V$ & .11 .9141 \\
\hline 199. & 190 & 148 & $11 \cdot v$ & 19 & $\cdot 1 \cdot \cdot \Delta \Lambda \cdot q$ & $r \cdot 10$ & IQV & If & 1.101 & Ifr & . \\
\hline 1991 & 911 & DQT & 1119 & $r \cdot$ &. $.9411 f$ & $r .19$ & rv. & TDS & 11.91 & 114 & . /. TYNAL \\
\hline 1995 & IVT & 191 & ITAF & IT & •/. • «द्व & $r \cdot I V$ & 91. & $\wedge 1$. & 9Tद. & $1 \ldots$ & $\cdot / \cdot r \cdot \Delta V Y$ \\
\hline 1994 & 111 & $\Lambda \cdot \Lambda$ & INFT & 1. & $\cdot / \cdot r \cdot \Delta V$ & $r \cdot 11$ & 1.09 & 919 & gTFT & $\vee \cdot$ & ./.rIF \\
\hline 1994 & $9 \Delta \wedge$ & १५५ & $\mid r q 1$ & tr &.$/$. gVYs & $r .19$ & TFQ & TrG & IIrAd & 119 & 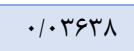 \\
\hline \multicolumn{12}{|c|}{ مجموع استنادات دريافتى: |\&DFA| } \\
\hline & & & & & دى: וצr & حود & & & & & \\
\hline
\end{tabular}


جدول r. رتبهبندى مجلات براساس ضريب تاثير قلمرو موضوعى كروناويروس

\begin{tabular}{|c|c|c|c|c|c|c|c|c|}
\hline عنوان منابع & استنادها & خالص استناد & استنادى & كشور & $\begin{array}{c}\text { ميزان اثركذارى مقاله } \\
\text { (Article Influence Score) }\end{array}$ & شاخص ايكنن & $\begin{array}{c}\text { ضريب تاثير } \\
\text { (Impact factor (IF)) }\end{array}$ & شاخص جارى \\
\hline $\begin{array}{l}\text { Proceedings of the National } \\
\text { Academy of Sciences of the } \\
\text { United States of America }\end{array}$ & 6403 & 6324 & 79 & USA & 4.493 & 1.02189 & 9.58 & Q1 \\
\hline Emerging infectious diseases & 4182 & 4094 & 88 & USA & 2.725 & 0.05940 & 7.185 & Q1 \\
\hline Journal of Infectious Disease & 2939 & 2889 & 50 & USA & 2.164 & 0.07596 & 5.045 & Q1 \\
\hline $\begin{array}{c}\text { Journal of Clinical } \\
\text { Microbiology }\end{array}$ & 2384 & 2329 & 55 & USA & 1.381 & 0.05332 & 4.959 & Q1 \\
\hline Journal of Virology & 37309 & 31575 & 5734 & USA & 1.381 & 0.09997 & 4.324 & Q1 \\
\hline Antiviral Research & 882 & 865 & 17 & Netherlands & 1.137 & 0.01597 & 4.13 & Q1 \\
\hline $\begin{array}{l}\text { The Journal of Biological } \\
\text { Chemistry }\end{array}$ & 2971 & 2916 & 55 & USA & 1.503 & 0.25223 & 4.106 & Q2 \\
\hline Viruses Basel & 888 & 863 & 25 & Switzerland & 1.221 & 0.02409 & 3.811 & Q2 \\
\hline Journal of Clinical Virology & 997 & 980 & 17 & Netherlands & 0.970 & 0.01530 & 3.02 & Q2 \\
\hline Journal of General Virology & 6498 & 6185 & 313 & England & 0.883 & 0.01877 & 2.809 & Q2 \\
\hline
\end{tabular}

است. مقادير بزرگتر از ا نشان دهنده اين است كه مقالات يك

$$
\text { مجله بيشتر از ميانگين كلى تاثير داشتهاند (Yr). }
$$

\section{يثوهشگران برتر قلمرو موضوعى كروناويروس}

در جدول ץ جزئيات · ا نويسنده برتر از بين

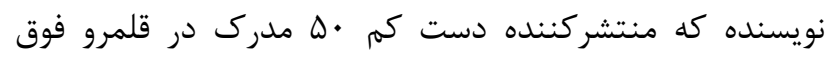

$$
\text { بودهاند، نشان داده شده است. }
$$

شكل س، رتبهبندى سازمانها و مراكز علمى برتر قلمرو

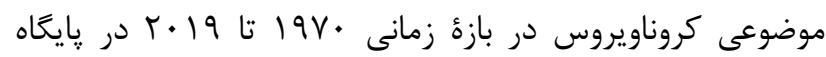

$$
\text { را نشان مى WoS }
$$

\section{سازمانها و مراكز علمى برتر قلمرو موضوعى كروناويروس}

شكل ץ ليست مراكز و سازمان هاى يرتوليد قلمرو كروناويروس

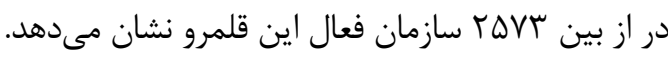

\section{تحليل استنادى قلمرو موضوعى كروناويروس}

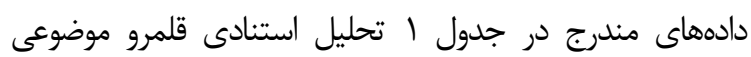

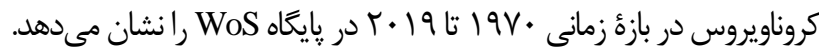

\section{مجلات برتر قلمرو موضوعى كروناويروس}

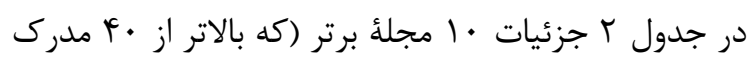
منتشر كردهاند) در قلمرو موضوعى كروناويروس ارائه شده است.

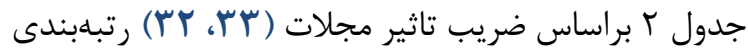
شده است. در جدول فوق، مى توان شاخص ايخن و ميزان اثر گذارى

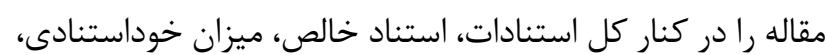
كشور منتشركننده مجله و مجلات را نيز مشاهده نمود. شاخص

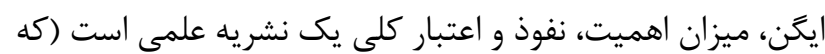

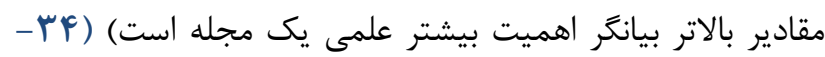

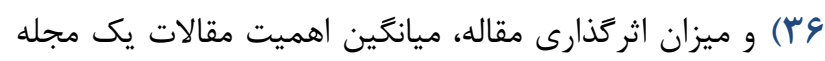

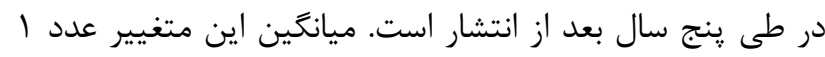

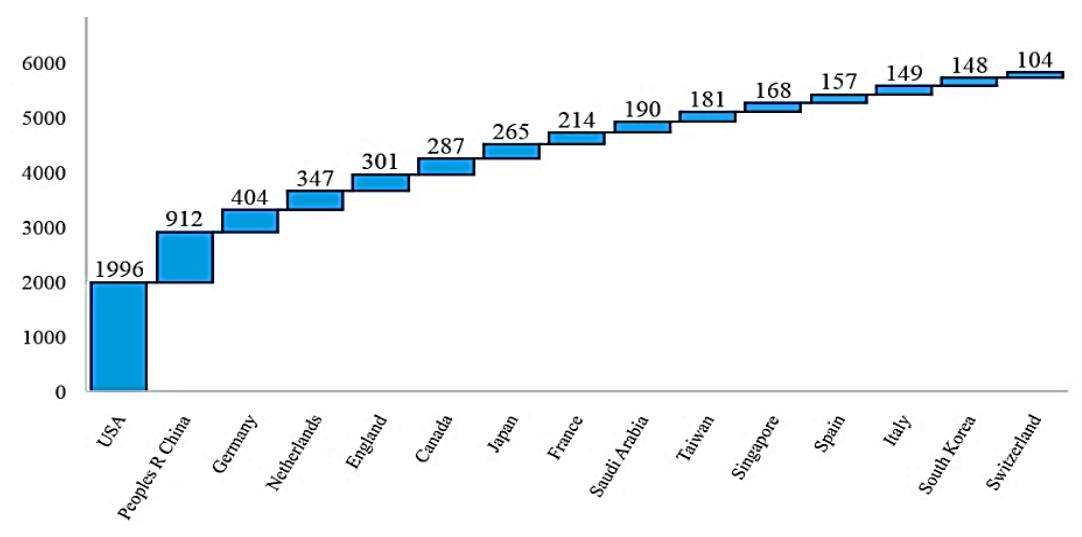

شكل r. كشورهاى تاثير كذار در قلمرو موضوعى كروناويروس ( • 19V-19 • ( ) 
The University of Hong Kong(HKU)

Chinese Academy of Sciences

Utrecht University

National Institutes of Health(NIH) USA

University of North Carolina

University of Würzburg

University of Pennsylvania

The University of Texas System

Consejo Superior de Investigaciones Científicas(CSIC)

University of California system

University of Iowa

University of North Carolina at Chapel Hill

Centers for Disease Control and Prevention USA

$\mathrm{NIH}$ National Institute of Allergy and Infectious

Leiden University

Johns Hopkins University

Ohio State University

National University of Singapore

University of Southern California

Centro Nacional de Biotecnología(CNB)

University of Quebec

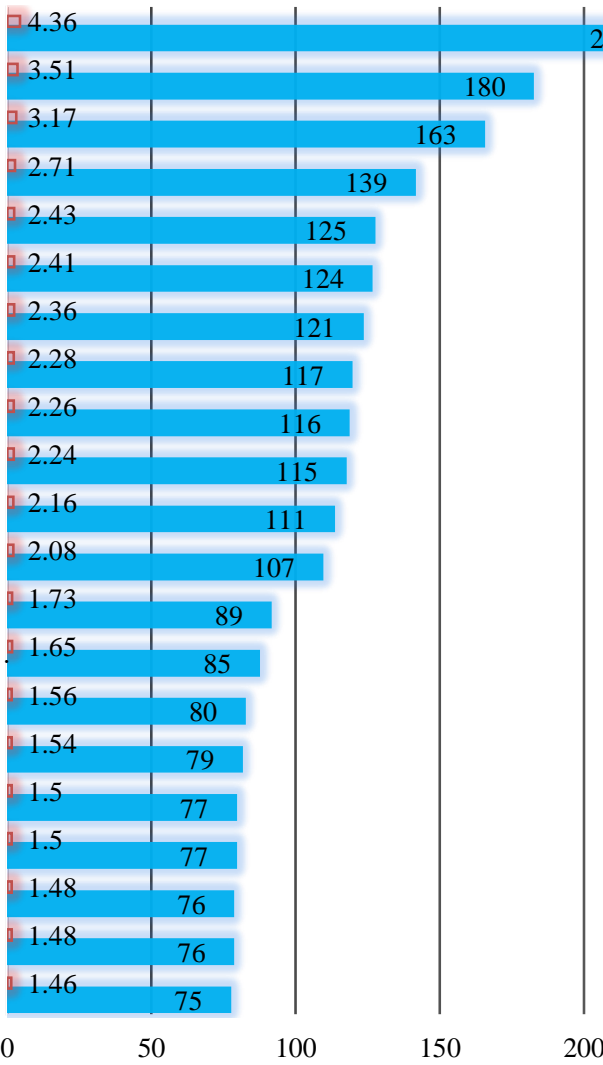

\begin{tabular}{|c|c|c|c|c|c|c|c|}
\hline نويسنده & وابستكى سازمانى & ركورد & $\%$ OF 5128 & اج ايندكس & استنادات & خوداستنادى & استناد خالص \\
\hline Enjuanes L & $\begin{array}{c}\text { Department of Molecular and Cell Biology, National } \\
\text { Center of Biotechnology (CNB-CSIC), Madrid, } \\
\text { Spain }\end{array}$ & 114 & T/YYT & fr & +1.0 & $9 . r$ & ro.r \\
\hline Perlman S & $\begin{array}{l}\text { Department of Microbiology and Immunology, } \\
\text { University of Iowa, Iowa City, Iowa, USA }\end{array}$ & $1 \cdot v$ & $Y / \cdot \wedge V$ & r4 & rqIF & $r 99$ & rAYA \\
\hline Weiss SR & $\begin{array}{c}\text { Department of Microbiology, Perelman School of } \\
\text { Medicine, University of Pennsylvania, Philadelphia, } \\
\text { PA, USA }\end{array}$ & १४ & l/A9r & ra & TEYT & roq & r990 \\
\hline Baric RS & $\begin{array}{c}\text { Department of Epidemiology, University of North } \\
\text { Carolina, Chapel Hill, NC, USA }\end{array}$ & 10 & $1 / 901$ & r4 & rava & rat & rrat \\
\hline Rottier PJM & $\begin{array}{l}\text { Virology Division, Department of Infectious Diseases } \\
\text { and Immunology, Utrecht University, Faculty of } \\
\text { Veterinary Medicine, Utrecht, the Netherlands }\end{array}$ & $\Delta F$ & $1 / 941$ & +1 & $01+9$ & req & rA... \\
\hline Drosten C & $\begin{array}{l}\text { Institute of Virology, Charité Universitätsmedizin, } \\
\text { Berlin, Germany. }\end{array}$ & Ar & $1 / 099$ & ra & 10.. & ४९१ & Ar.l \\
\hline Liu DX & $\begin{array}{l}\text { Guangdong Province Key Laboratory of Microbial } \\
\text { Signals \& Disease Control, and Integrative } \\
\text { Microbiology Research Centre, South China } \\
\text { Agricultural University, Guangzhou, China }\end{array}$ & VT & I/FYF & $r$. & $1149 V$ & roo & IFIr \\
\hline Makino S & $\begin{array}{c}\text { Department of Microbiology and Immunology, The } \\
\text { University of Texas Medical Branch, Galveston, } \\
\text { Texas, USA }\end{array}$ & VY & $1 / 4 \cdot 4$ & r & rq. r & ros & rofG \\
\hline Woo PCY & $\begin{array}{c}\text { State Key Laboratory of Emerging Infectious Diseases, } \\
\text { The University of Hong Kong, Pokfulam, Hong } \\
\text { Kong }\end{array}$ & $4 V$ & $1 / \mu \cdot v$ & re & PAT & $\Delta \Delta \lambda$ & GeVt \\
\hline
\end{tabular}




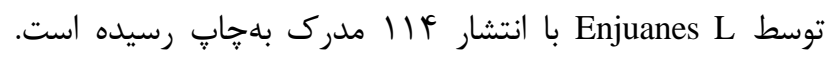

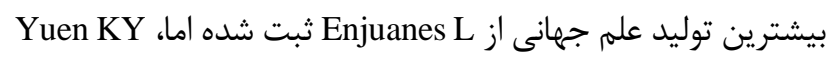

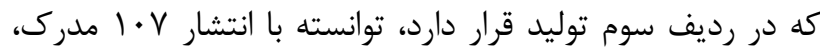

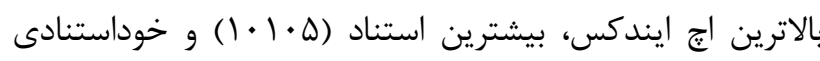

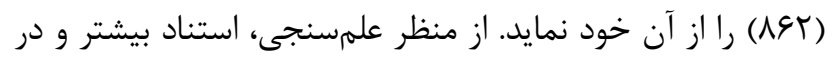
يى آن افزايش شاخص اجايندكس، لزوما بهمفهوم ارزش و كيفيت

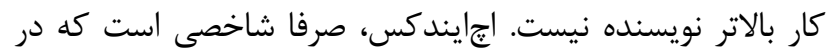

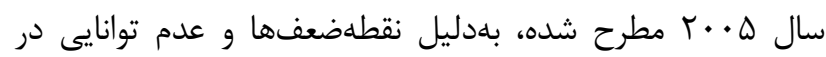
تشخيص صحيح تا بهامروز نقدهاى زيادى بر آن شده همواره شاخصهاى جديدترى جون إج آلفا (h/)، إج إى (hA-index)

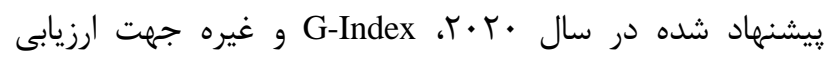
وضعيت نويسند برتر و يرتوليد قلمرو كروناويروس داراى بالاترين اج ايندكس و يات استناد نيست. اين نشاندهنده اين است كه إج ايندكس مى تواند با يأ

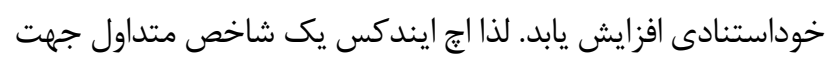

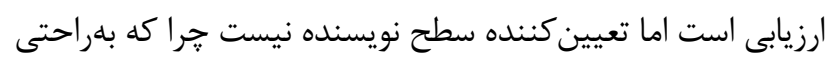

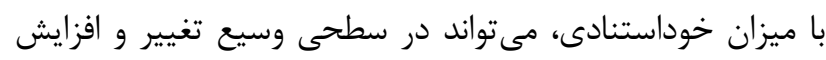

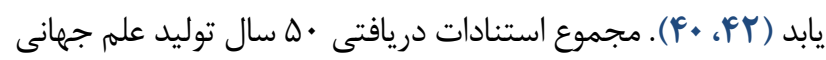
كروناويروس در جدول | برابر با |هأDاع| بوده كه از اين تعداد ו يكى از مهممترين شاخصهاى ارزيابى كيفيت مجلات قلمداد مىشود

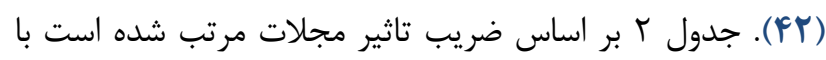
اين وجود دو شاخص مطرح يعنى ايگن فاكتور و ميزان اثركذارى مقاله كه در سالهاى اخير در دنيا بسيار مطرح بوده نيز ارائه شده است كه جهت سنجش و ارزيابى مجلات قابل بررسى است. در كنار شاخصهاى IF ارائه شده امكان بررسى سطح Q مجلات برتر قلمرو نيز وجود دارد. مجلاتى كه داراى IF هستند در بخش ايخن فاكتور

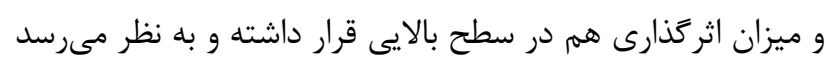

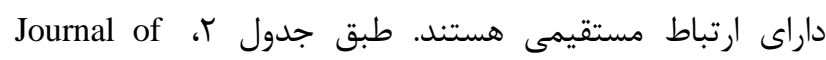
بالاترين استناد كل را داراست اما موثرترين نشريه اين

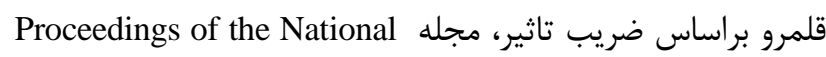
Academy of Sciences of the United States of America جزو نشريات Q1 است. دانشعاه University of Hong Kong، دانشعاه برتر و فعال قلمرو موضوعى كروناويروس در اين يثوهش نش

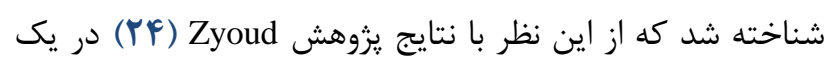

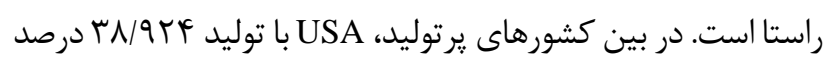

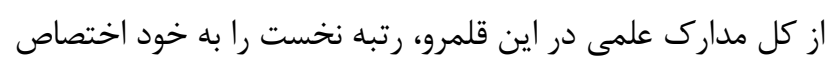

نتايج حاكى از آن است كه در • ه سال اخير، بيشترين توليد

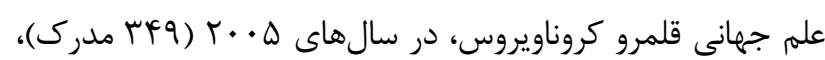

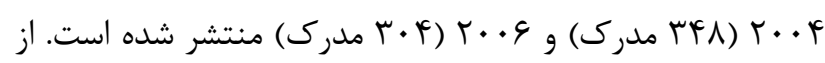

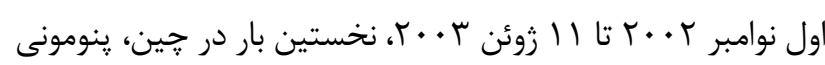

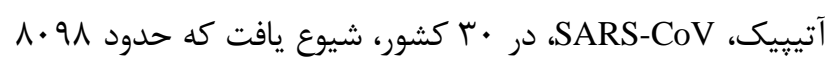
تن را به بيمارى مبتلا و حدود \&19 تن را به كام مرگ كشيد. دورة

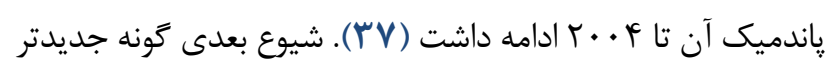

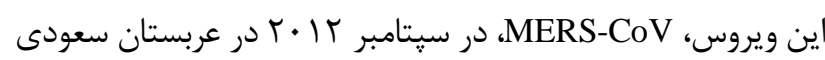

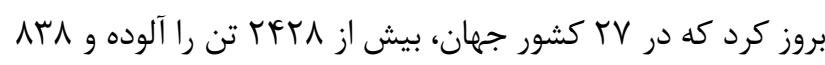
فوت را بههمراه داشت و سيس شيوع مجدد آن در ها ها • در در

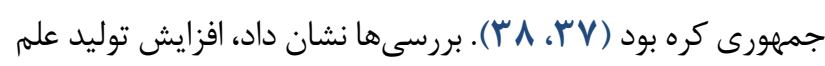
جهانى قلمرو مذكور در اين سالها متأثر از رويدادها و كوشش

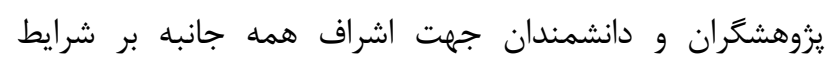
إييدميك و رياندميك ويروس فوق بوده است. nCoV-2019 كه به

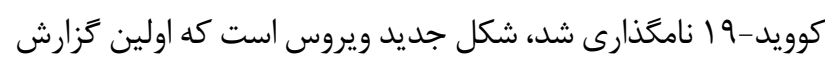

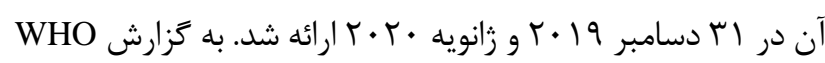
شمار قربانيان آن تاكنون از مرز . .ب تن كذاشته است (سا). آنجه از بررسىها درك مىشود اين است كه، همواره بين Outbreak هاى كرونا ويريده، بالتبع آن تعداد مبتلايان و مرگ و مير ناشى آنى از كرونا ويريده و تعداد انتشار مقالات رابطه مستقيمى وجود دارد. از نظر

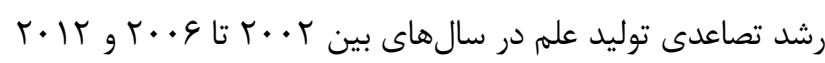

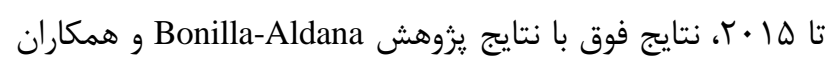

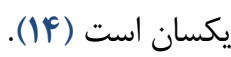

تحليل استنادى، از جمله كارهاى استنادى است كه رابطه بين

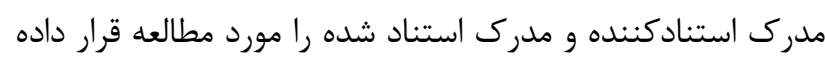
و بلبررسى قواعد حاكم بر اين رابطه مىيردازد. خوداستنادى يا

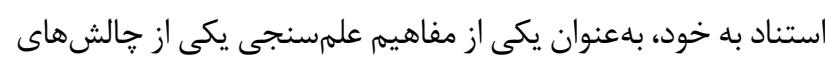

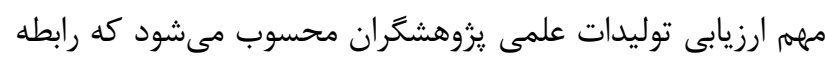

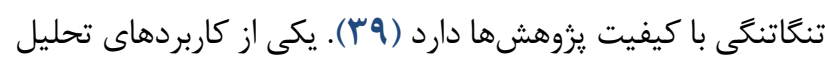

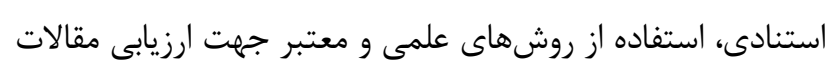

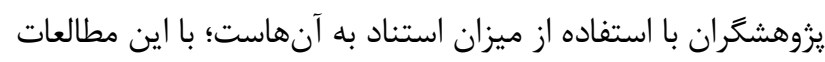
مى توان به ميزان فعاليت علمى و يزوهشى افراد و ميزان اثربخشى و تأثيركذارى مطالعات آنها بيىبرد و از طرفى تحليل استى استنادى

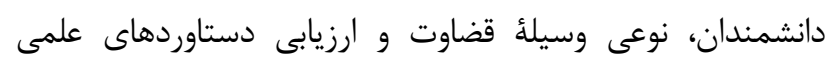

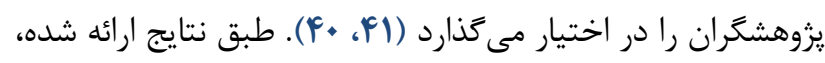

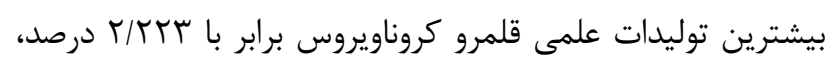




$$
\begin{aligned}
& \text { در شرايط كنونى در حال يزوهش روى COVID19 در مراكز } \\
& \text { يزوهشى هستند، خصوصا متخصصين ايرانى، كمك شايانى نمايد. } \\
& \text { آكاهى و آشنايى با نتايج مطالعات علمسنجى موضوعهاى } \\
& \text { راهبردى مانند كروناويروس، براى يزوهشكران، سياست }
\end{aligned}
$$

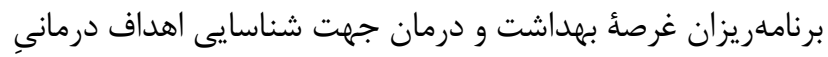

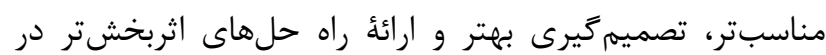

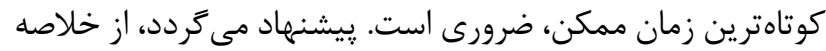

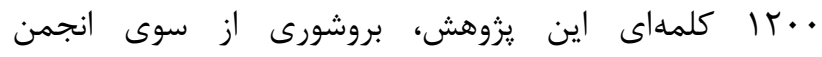

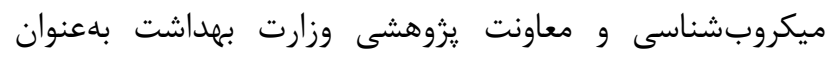

$$
\begin{aligned}
& \text { راهنماى علمى براى يزوهشكران تهيه و در فضاى مجازى در سطح } \\
& \text { كسترده منتشر شود. } \\
& \text { سياسگزارى }
\end{aligned}
$$

بدينوسيله، از متخصصان بيمارىهاى عفونى و تنفسى

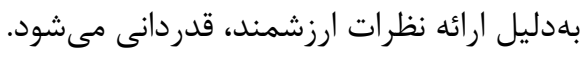

$$
\text { تعارض در منافع }
$$

اين مقاله يزوهشى مستقل است كه بدون حمايت مالى إنى

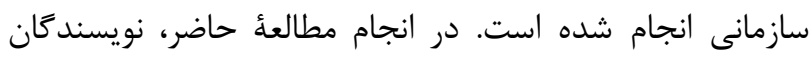

هيج كونه تضاد منافعى نداشتهاند.

\section{Referance}

1. World Health Organization (WHO). Novel Coronavirus (2019-nCoV). Available

at:

https://www.who.int/docs/default-

source/coronaviruse/situation-reports/20200211-sitrep-

22-ncov.pdf (accessed on 14 February 2020).

2. Gralinski EL ،Menachery VD. Return of the Coronavirus:

2019-nCoV. Viruses, 2020; 12(2): 135. [DOI:10.3390/v12020135] [PMID]

3. Zhu Z, Zhang Z, Chen W, Cai Z, Ge X, Zhu H, Jiang T, Tan $\mathrm{W}$, and Peng Y. Predicting the receptor-binding domain usage of the coronavirus based on kmer frequency on spike protein. Infection, genetics, and evolution: journal of molecular epidemiology and evolutionary genetics in infectious diseases. 2018 Jul; 61:183-4. [DOI:10.1016/j.meegid.2018.03.028] [PMID]

4. Li G, Fan Y, Lai Y, Han T, Li Z, Zhou P, Pan P, Wang W, Hu D, Liu X, Zhang Q. Coronavirus Infections, and Immune Responses. Journal of Medical Virology. 2020 Jan 25. [DOI:10.1002/jmv.25685] [PMID]

5. Zhao S, Musa SS, Lin Q, Ran J, Yang G \& et al. Estimating the Unreported Number of Novel Coronavirus (2019-nCoV) Cases in China in the First Half of January 2020: A Data-Driven Modelling Analysis of the Early
داده است. كشورهاى جين و آلمان نيز به ترتيب در جايگاه دوم و

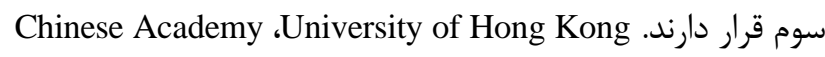
National Institutes of ،Utrecht University of Sciences University of North Carolina و Health (NIH) هستند كه بيشترين مدارك علمى كروناويروس را منتشر كردهاند و در جايعاههاى نخست تا ينجم قرار دارند. از نظر افزايش كمّى فعاليتها و توليد علم قلمروهاى

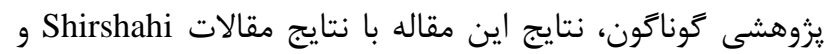

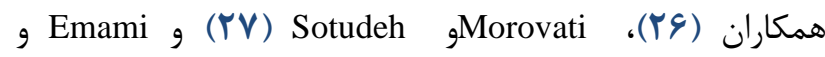

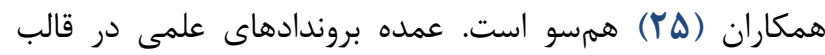
مقالات يزوهشى، بهجاٍ رسيدهاند كه از اين بُعد نيز، نتايج مقاله

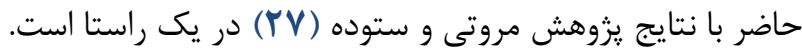

$$
\text { نتيجه }
$$

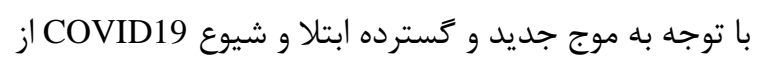

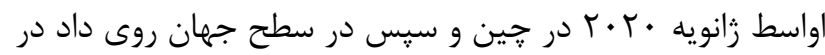
راستاى يافتن روشهاى درمانى يا كشف واكسن يا داروهاى جديد

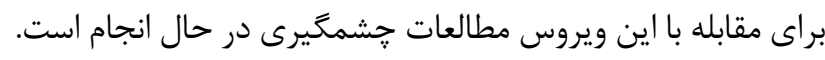

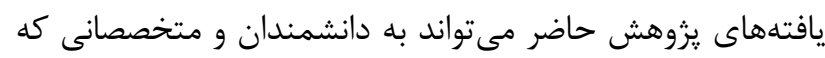

Outbreak. J. Clin. Med, 2020; 9(2): 388. [DOI:10.3390/jcm9020388] [PMID]

6. Wang M, Cao R, Zhang L \& et al. Remdesivir and chloroquine effectively inhibit the recently emerged novel coronavirus (2019-nCoV) in vitro. Cell Res, 2020. [DOI:10.1038/s41422-020-0282-0] [PMID] [PMCID]

7. Minjin W, Yanbing Z, Zhiyong Z, Zongan L, Yu C, Hong T, Bin S, Zixing H, Yan K, Ping F, Binwu Y, Weimin L. A precision medicine approach to managing Wuhan Coronavirus pneumonia. Precision Clinical Medicine, 2020, pbaa002,

8. Liu J, Zheng X, Tong Q, Li W, Wang B, Sutter K, Trilling $\mathrm{M}$, Lu M, Dittmer U and Yang D. Overlapping and discrete aspects of the pathology and pathogenesis of the emerging human pathogenic coronaviruses SARS-CoV, MERS-CoV, and 2019-nCoV. J Med Virol, 2020; Accepted Author Manuscript. [DOI:10.1002/jmv.25709] [PMID]

9. Daszak P, Olival KJ, Li H. A strategy to prevent future pandemics similar to the 2019-nCoV outbreak. Biosafety and Health, 2020; in Press, Elsevier. [DOI:10.1016/j.bsheal.2020.01.003] 
10. Tavakoli A, Karbalaie Niya M H, Keshavarz M, Safarnezhad Tameshke F, Monavari S H. Middle East Respiratory Syndrome Coronavirus (MERS-CoV). Iran J Med Microbiol, 2017; 11 (1):1-8.

11. Momattin H, Al-Ali AY, Al-Tawfiq JA. A Systematic Review of therapeutic agents for the treatment of the Middle East Respiratory Syndrome Coronavirus (MERSCoV). Travel Medicine and Infectious Disease, 2019; 30: 9-18. [DOI:10.1016/j.tmaid.2019.06.012] [PMID]

12. Vahdat K, Amini A, Najafi A, HaerNejad M J. A Review of Novel Coronavirus, cause of Middle East Respiratory Syndrome. Iran South Med J Bimonthly, 2014; 16 (6):486-492. (Persian)

13. Cui J, Li F \& Shi Z. Origin and evolution of pathogenic coronaviruses. Nature Reviews Microbiology (Nat Rev Microbiol), 2019; 17: 181-192. [DOI:10.1038/s41579018-0118-9] [PMID]

14. Bonilla-Aldana DK, Quintero-Rada K, Montoya-Posada JP, Ramirez S, Paniz-Mondolfi A, Rabaan A, Sah R, Rodríguez-Morales AJ. SARS-CoV, MERS-CoV and now the 2019-novel CoV: Have we investigated enough about coronaviruses?-A bibliometric analysis. Travel medicine and infectious disease. 2020 Jan 30:101566. [DOI:10.1016/j.tmaid.2020.101566] [PMID]

15. Nishiura H, Kobayashi T, Yang Y, Hayashi K, Miyama T, Kinoshita R, Linton NM, Jung SM, Yuan B, Suzuki A, Akhmetzhanov AR. The Rate of Underascertainment of Novel Coronavirus (2019-nCoV) Infection: Estimation Using Japanese Passengers Data on Evacuation Flights. J. Clin. Med, 2020; 9, 419. [DOI:10.3390/jcm9020419] [PMID]

16. Yazdani K, Rahimi-Movaghar A, Nedjat S, Ghalichi L, Khalili M. A 5-year scientometric analysis of research centers affiliated to Tehran University of Medical Sciences. Med J Islam Repub Iran, 2015; 29 (1): 375-384.

17. Yazdani K, Nejat S, Rahimi-Movaghar A, Ghalichee L, Khalili M. Scientometrics: Review of Concepts, Applications, and Indicators. Iranian Journal of Epidemiology (IJE), 2015; 10 (4): 78-88. (Persian)

18. Molinari A, Molinari JF. Mathematical aspects of a new criterion for ranking scientific institutions based on the hindex. Scientometrics, 2008; 75(2): 339-56. [DOI:10.1007/s11192-007-1872-z]

19. Molinari JF, Molinari A. A new methodology for ranking scientific institutions. Scientometrics. 2008; 2008; 75(1):163-74. [DOI:10.1007/s11192-007-1853-2]

20. Rezagholizadeh A, Shayanfar A, Hanaee J, Jouyban A. Scientometric evaluation of pharmaceutical chemistry departments of faculties of pharmacy in Iran. Description of Health 2017; 8(2): 75-87. (Persian)

21. Ivancheva LE. Scientometrics Today: A Methodological Overview. Collnet Journal of Scientometrics and Information Management, 2008; 2: 47-56. [DOI:10.1080/09737766.2008.10700853]
22. Makkizadeh F \& Sa'adat F. Bibliometric and thematic analysis of articles in the field of infertility (2011-2015). International journal of reproductive biomedicine (Yazd, Iran) 2017; 15(11): 719-728. (Persian) [DOI:10.29252/ijrm.15.11.719]

23. Singh N, Brar RS, Chavan SB \& Singh J. Scientometric analyses and visualization of a scientific outcome on the Nipah virus. CURRENT SCIENCE (A Fortnightly Journal of Research), 2019; 117(10). [DOI:10.18520/cs/v117/i10/1574-1584]

24. Zyoud SH. Global research trends of Middle East respiratory syndrome coronavirus: a bibliometric analysis. BMC Infect Dis, 2016; 16, 255. [DOI:10.1186/s12879016-1600-5] [PMID] [PMCID]

25. Danesh F, Ghavidel S. Visualizing the Clusters and Dynamics of HPV Research Area. Iran J Med Microbiol, 2019; 13 (4):266-278. [DOI:10.30699/ijmm.13.4.266]

26. Khasseh A, Fakhar M, Soosaraei M, Sadeghi S. Evaluation of scientific performance of Iranian researchers in parasitology domain in ISI databases. Iran J Med Microbiol, 2011; 4 (4):41-50.

27. Emami Z, Hariri N, Khamseh M E, Nooshinfard F. Mapping diabetes research in Middle Eastern countries during 2007-2013: A scientometric analysis. Medical Journal of the Islamic Republic of Iran, Med J Islam Repub Iran, 2018; $32 \quad$ (1):486-494. [DOI:10.14196/mjiri.32.84] [PMID] [PMCID]

28. Shirshahi S \& et al. mapping the structure of surgery discipline in the Science Citation Index. Isfahan University of Medical Sciences, Health Information Management (Health Inf Manage), 2014; 11(7): 830-839.

29. Morovati M, Sotudeh H. Scientific Productivity in Neonates' Health Field in Scopus. Int J Pediatr, 2016; 4(6): $1837-1846$

30. Soheili F, Danesh F, Mesrinejad F \& Isfandyari Moghadam A. Lotka's Law of Scientific Productivity and Bradford's Law of Scatter among Researchers at Isfahan University of Medical Sciences based on Web of Science Database. Isfahan University of Medical Sciences, Health Information Management (Health Inf Manage (2012; 8(6): 766-773.

31. Birkle C, Pendlebury DA, Schnell J \& Adams J. Web of Science as a data source for research on scientific and scholarly activity. Quantitative Science Studies, 2020; 1(1), 363-376. [DOI:10.1162/qss_a_00018]

32. Clarivate Analytics, available at https://clarivate.com/webofsciencegroup/essays/impactfactor/ (access Feb 12, 2020).

33. Grech V, Rizk DEE. Increasing importance of research metrics: Journal Impact Factor and h-index. Int Urogynecol J, 2018; 29: 619-620. [DOI:10.1007/s00192018-3604-8] [PMID] 
34. Eigenfactor, available at http://www.eigenfactor.org (access March 6, 2020).

35. Bergstrom TC, West JD, Wiseman MA. The Eigenfactor $^{\mathrm{TM}}$ Metrics. The Journal of Neuroscience ( $\mathrm{J}$ Neurosci), 2008; 28(45): 11433-11434. [DOI:10.1523/JNEUROSCI.0003-08.2008] [PMID] [PMCID]

36. Bergstrom C. Eigenfactor: measuring the value and prestige of scholarly journals. C\&RL News, 2007; 314316. [DOI:10.5860/crln.68.5.7804]

37. Song Z, Xu Y, Bao L, Zhang L, Yu P, Qu Y, Zhu H, Zhao W, Han Y, Qin C. From SARS to MERS, Thrusting Coronaviruses into the Spotlight. Viruses, 2019; 11(1): 59. [DOI:10.3390/v11010059] [PMID] [PMCID]

38. Leist SR, Jensen KL, Baric RS, Sheahan TP. Increasing the translation of mousemodels of MERS coronavirus pathogenesisthrough kinetic hematological analysis. PLoS ONE, 2019; 14(7): e0220126. [DOI:10.1371/journal.pone.0220126] [PMID] [PMCID]

39. Noroozi chakoli A, Jafari S. Analytical assessment of the relationship between the quality and self-citation in Persian Humanities Journals. Caspian Journal of Scientometrics) CJS(. 2014; 1 (2): 57-65.

40. Hirsch JE. ha: An index to quantify an individual's scientific leadership. Scientometrics, 2019; 118, 673-686. [DOI:10.1007/s11192-018-2994-1]

41. dehghanizadeh M, Haji Zeinolabedini M, hasanzadeh M. Citation analysis of the arti-cles from the faculty members of Tehran University indexed in Islamic World Science Citation Center (ISC), 2006-2011. Scientometrics Research Journal (Scientific Bi-Quarterly of Shahed University), 2016; 2(3): 99-111.

42. Shaibu M, Anthony M \& Emmanuel N. On the influence of uncited publications on a researcher's h-index. Scientometrics, Springer; Akadémiai Kiadó, 2020; 122(3): 1791-1799. [DOI:10.1007/s11192-020-03356-1] 